Article

\title{
Use of the Wilshire Equations to Correlate and Extrapolate Creep Data of Inconel 617 and Nimonic 105
}

\author{
Vito Cedro III ${ }^{1, *}$,, Christian Garcia ${ }^{2}(\mathbb{D})$ and Mark Render ${ }^{3}(\mathbb{C})$ \\ 1 National Energy Technology Laboratory, 626 Cochrans Mill Road, Pittsburgh, PA 15236, USA \\ 2 Mechanical Engineering Department, University of Texas Rio Grande Valley, 1201 West University Drive, \\ Edinburg, TX 78539, USA; christian.garcia03@utrgv.edu \\ 3 KeyLogic Systems, Inc., 3168 Collins Ferry Road, Morgantown, WV 26505, USA; mrender@keylogic.com \\ * Correspondence: vito.cedro@netl.doe.gov; Tel.: +1-412-386-7406
}

Received: 16 November 2018; Accepted: 11 December 2018; Published: 13 December 2018

check for updates

\begin{abstract}
Advanced power plant alloys must endure high temperatures and pressures for durations at which creep data are often not available, necessitating the extrapolation of creep life. A recently developed creep life extrapolation method is the Wilshire equations, with which multiple approaches can be used to increase the goodness of fit of available experimental data and improve the confidence level of calculating long-term creep strength at times well beyond the available experimental data. In this article, the Wilshire equation is used to extrapolate the creep life of Inconel 617 and Nimonic 105 to 100,000 h. The use of (a) different methods to determine creep activation energy, (b) region splitting, (c) heat- and processing-specific tensile strength data, and (d) short-duration test data were investigated to determine their effects on correlation and extrapolation. For Inconel 617, using the activation energy of lattice self-diffusion as $Q_{C}^{*}$ resulted in a poor fit with the experimental data. Additionally, the error of calculated rupture times worsened when splitting regions. For Nimonic 105, the error was reduced when heat- and processing-specific tensile strengths were used. Extrapolating Inconel 617 creep strength to $100,000 \mathrm{~h}$ life gave conservative results when compared to values calculated by the European Creep Collaborative Committee.
\end{abstract}

Keywords: Wilshire equation; Larson-Miller parameter; creep strength; Inconel 617; Nimonic 105; time to rupture

\section{Introduction}

Innovations in power generation require materials that are capable of withstanding high temperatures and stresses for at least 100,000 h of operation time. The high temperatures and pressures found in advanced power plants can induce creep failure in alloys. Consequently, alloys must be tested so that creep failures are avoided during service. However, data regarding creep of new advanced power plant alloys are often not available at times relevant to the required design life. In particular, nickel-based superalloys - promising alloys for ultra-supercritical power plant applications-have no creep rupture data at 100,000 $\mathrm{h}$ in the literature. The longest creep rupture test of a nickel-based superalloy known to the authors-an Inconel 617 specimen last reported at 90,936 h-is ongoing and is the result of a joint effort led by the U.S. Department of Energy and the Ohio Coal Development Office [1,2]. The same effort produced creep rupture data for Inconel 617 to $43,706 \mathrm{~h}$ (completed), and Inconel 740 to $30,957 \mathrm{~h}$ (completed) and 56,550 h (ongoing). In a similar effort, creep rupture data of Nimonic 105 was generated to $34,955 \mathrm{~h}[3,4]$. Hence, extrapolating the creep life of these alloys is necessary to determine if they are suitable for use. 
Various methods have been proposed to extrapolate creep life. The Wilshire equations [5] are a recently-developed extrapolation method that has been used to predict long-term creep behavior of high-temperature, creep-resistant alloys [6]. Different approaches have been used to fit the Wilshire equation to creep rupture data. In this article, the Wilshire equation for time to rupture and the Larson-Miller parameter (LMP) equation are used to correlate and extrapolate the creep life of two nickel-based superalloys, Inconel 617 and Nimonic 105. The Wilshire equation's goodness of fit and the error of the calculated rupture times resulting from the use of different creep activation energy $\left(Q_{C}^{*}\right)$ values determined by various methods are compared. This article also investigates the effect of splitting creep rupture data into above- and below-yield stress regions, the effect of heat- and processing-specific tensile strength (TS) values, and examines the ability of the Wilshire equation to predict creep life greater than 10,000 h using data with rupture times less than 10,000 h. Additionally, the calculations of the Wilshire and LMP equations are compared. The paper is constructed as follows: Section 2 gives a brief overview of the Wilshire and LMP equations; Section 3 discusses the data sets and methods used to obtain $Q_{C^{\prime}}^{*}$ split stress regions, and how Larson-Miller fitting parameters were obtained; Section 4 outlines the calculations and results of the study; and the final section presents conclusions.

\section{Wilshire and Larson-Miller Parameter Equations}

The classic power law equation, which is a combination of the Arrhenius [7] and Norton [8] equations, is the most established description of the creep of materials. The equation is defined as:

$$
\dot{\varepsilon}_{m}=A \sigma^{n} e^{-Q_{C} / R T},
$$

where $\dot{\varepsilon}_{m}$ is the minimum creep rate, $A$ is a material parameter, $\sigma$ is applied stress, $n$ is the stress exponent, $Q_{C}$ is the creep activation energy, $R$ is the universal gas constant, and $T$ is absolute temperature. The Monkman-Grant equation [9] is defined as:

$$
\dot{\varepsilon}_{m}^{\alpha} t_{r}=C_{M}
$$

where $t_{r}$ is the time to rupture, $C_{M}$ is a constant, and $\alpha$ is the slope of $\log t_{r}$ vs. $\log \dot{\varepsilon}_{m}$. This equation can be coupled with Equation (1), with $\alpha$ set equal to 1, to produce the following time-to-rupture-based version of the classic power law equation

$$
t_{r}=\frac{C_{M}}{A \sigma^{n} e^{-Q_{C} / R T}} .
$$

However, this equation is unreliable for predicting creep life at temperatures, stresses, and durations at which there are no experimental data available. This is due to the changing and difficult-to-predict stress exponent $[10,11]$, which is a function of stress and temperature. Additionally, creep activation energy is a function of applied stress. Therefore, a creep activation energy that has been calculated in one stress region cannot be extrapolated to another. Many techniques to extrapolate creep life reliably from limited data have been proposed [12,13], including the relatively new Wilshire equation and the well-established Larson-Miller parameter equation.

\subsection{Wilshire Equation}

In 2007, Wilshire and Battenbough [5] developed a physically-based yet fairly simple method to represent creep life as a function of applied stress and temperature in uniaxial tests. The proposed equations are:

$$
\begin{aligned}
\frac{\sigma}{\sigma_{T S}} & =\exp \left(-k_{1}\left[t_{r} \exp \left(-\frac{Q_{C}^{*}}{R T}\right)\right]^{u}\right), \\
\frac{\sigma}{\sigma_{T S}} & =\exp \left(-k_{2}\left[\dot{\varepsilon}_{m} \exp \left(\frac{Q_{C}^{*}}{R T}\right)\right]^{v}\right) .
\end{aligned}
$$




$$
\frac{\sigma}{\sigma_{T S}}=\exp \left(-k_{3}\left[t_{\varepsilon} \exp \left(-\frac{Q_{C}^{*}}{R T}\right)\right]^{w}\right)
$$

where $\sigma / \sigma_{T S}$ is the ratio of applied stress to ultimate tensile strength, $t_{r}$ is time to rupture, $\dot{\varepsilon}_{m}$ is minimum creep rate, $t_{\varepsilon}$ is time to strain, $Q_{C}^{*}$ is creep activation energy determined at constant $\sigma / \sigma_{T S}, R$ is the universal gas constant, $T$ is absolute temperature, and $k_{1}, u, k_{2}, v, k_{3}$, and $w$ are fitting constants. Heat- and processing-specific tensile strength values may be used if data were collected from specimens of multiple heats. Applied stress can be normalized by yield strength $\left(\sigma_{Y S}\right)$, but normalization by ultimate tensile strength causes the stress ratio to always lie between zero and one. The boundaries of the Wilshire equations are

$$
t_{r} \rightarrow 0, \dot{\varepsilon}_{m} \rightarrow \infty, t_{\varepsilon} \rightarrow 0 \text { when } \frac{\sigma}{\sigma_{T S}} \rightarrow 1, t_{r} \rightarrow \infty, \dot{\varepsilon}_{m} \rightarrow 0, t_{\varepsilon} \rightarrow \infty \text { when } \frac{\sigma}{\sigma_{T S}} \rightarrow 0 .
$$

\subsection{Larson-Miller Parameter Equation}

A common method used to extrapolate creep life is the Larson-Miller parameter equation [14], which predates the Wilshire equation by half a century. The LMP equation is:

$$
\mathrm{LMP}=T\left(\log _{10}\left(t_{r}\right)+C\right),
$$

where $T$ is absolute temperature, $C$ is a material constant, and $t_{r}$ is time to rupture. The LMP, a function of stress, is often described by the following fitting function.

$$
\operatorname{LMP}(\sigma)=B_{0}+B_{1} \log (\sigma)+B_{2} \log (\sigma)^{2}+B_{3} \log (\sigma)^{3}+\ldots B_{m} \log (\sigma)^{m} .
$$

\section{Methods}

\subsection{Data}

The Wilshire and Larson-Miller parameter equations both require the following data from creep rupture tests: temperature, applied stress, and time to rupture. Additionally, the Wilshire equation requires the material's ultimate tensile strength at each test temperature. Yield strength values are not included in the Wilshire equations, but according to Wilshire and Battenbough [5] can be used to group high- and low-stress data for analysis. Data were obtained from tables or extracted from plots in various publications using Dagra digitization software (version 2.0.12) [15].

\subsubsection{Inconel 617}

Inconel 617 tensile and yield strength data were obtained and extracted from a conference presentation [16]. The data is composed of multiple datasets and there is noticeable scatter in the plotted data. A trendline of the average tensile strength of the combined datasets was used for the extraction of data. Creep test data were extracted from five sources [1,17-20], the longest of which extends to $43,706 \mathrm{~h}$. A total of 420 creep rupture data points were extracted; 386 have a rupture time less than 10,000 $\mathrm{h}$ and 354 have an applied stress less than yield strength.

\subsubsection{Nimonic 105}

For Nimonic 105, tensile and yield strength values and creep rupture data were obtained from two technical reports [3,4] and email correspondence with one of their authors [21]. Specimens with the following processing conditions were tested at temperatures from 760 to $816^{\circ} \mathrm{C}$ for up to $34,955 \mathrm{~h}$ : as-processed (AP), peak-aged (PA), and over-aged (OA). Heat- and processing-specific tensile and yield strength values are available at 760 and $816^{\circ} \mathrm{C}$. Linear interpolation was used to calculate tensile and yield strength values at intermediate temperatures. Of the 33 specimens, eight were aged at $774{ }^{\circ} \mathrm{C}$ for one or two years prior to testing. It is not known which of the eight specimens were aged for each timeframe, so tensile and yield strength values for both timeframes were averaged. Tensile and yield 
strength values at 760 and $816^{\circ} \mathrm{C}$ for each heat and processing condition are shown in Table A1 of Appendix A. All data points have an applied stress less than yield strength and 16 data points have a rupture time less than 10,000 $\mathrm{h}$. The overall scatter of the data is low compared to that of Inconel 617.

\subsection{Wilshire Equation}

Although three versions of the Wilshire equation exist, in this study Equation (4)-the Wilshire equation for time to rupture-is used. Several methods have been used in the literature to determine $Q_{C}^{*}$. In this work, $Q_{C}^{*}$ was determined using multiple methods.

First, $Q_{C}^{*}$ values were determined using Arrhenius plots. This method is the most well-known, and it is assumed [22] that Wilshire used this method in his papers [4,5,23-31]. For this approach, existing creep data is regressed and rupture times at constant stress ratios are calculated. This work uses least squares regression and stress ratios at every tenth value (i.e., $\sigma / \sigma_{T S}=0.1,0.2,0.3$, etc.) with suitable data at each test temperature. Next, an Arrhenius plot of the natural log of time to rupture vs. the inverse absolute temperature is generated. For each stress ratio, a $Q_{C}^{*}$ value is defined as the slope of a line of best fit multiplied by the universal gas constant. An average is then taken of all $Q_{C}^{*}$ values to determine the final $Q_{C}^{*}$ value.

Second, $Q_{C}^{*}$ values were determined by optimizing the correlation of data on a Wilshire plot $\left(\ln \left[t_{r} \exp \left(-Q_{C}^{*} / R T\right)\right]\right.$ vs. $\left.\ln \left[-\ln \left(\sigma / \sigma_{T S}\right)\right]\right)$, as performed by Whittaker [32-34] and Jeffs [35]. When calculating $Q_{C}^{*}$ using an Arrhenius plot, the delta between the stress ratios influences the final average $Q_{C}^{*}$ value (e.g., $\sigma / \sigma_{T S}=0.1,0.2$ and 0.3 compared to $\sigma / \sigma_{T S}=0.1,0.15,0.2,0.25$, and 0.3 ). This presents a concern when calculating an average $Q_{C}^{*}$, since the stress ratios are not mathematically derived, but chosen based on the judgement of the user. Determining $Q_{C}^{*}$ by optimizing the correlation of data on a Wilshire plot eliminates concern over the variance of $Q_{C}^{*}$ at arbitrarily-chosen stress ratios. The technique used to optimize the correlation of data is generally not defined in the literature and may vary between authors. In this work, $Q_{C}^{*}$ values ranging from 1 to $500 \mathrm{~kJ} / \mathrm{mol}$ were iterated with a step size of $1 \mathrm{~kJ} / \mathrm{mol}$ to find the best correlation, which was quantified by the coefficient of determination $\left(\mathrm{R}^{2}\right)$.

Third, in some articles $[5,24-29,32,36]$ the reasonableness of the calculated value of $Q_{C}^{*}$ is assessed by comparing it to an experimentally-measured or theoretically-calculated activation energy of lattice self-diffusion. If a value for the activation energy of lattice self-diffusion is known, it may be expedient to use this value as $Q_{C}^{*}$ rather than calculate a value from the experimental data.

After $Q_{C}^{*}$ has been determined, the $u$ and $k_{1}$ fitting constants are respectively defined as the slope and exponential of the $y$-intercept of a best fit line on a Wilshire plot. Multiple linear regions may be visible on this plot, which would suggest that the data be separated into regions to improve the goodness of fit of the Wilshire equation. Gray and Whittaker [37] point out that Wilshire split regions using two different methods. Regions were consistently split where $\sigma$ was equal to $\sigma_{Y S}$, but in one case, $Q_{C}^{*}$ and new fitting constants were recalculated for each region [33], while in another case, the original $Q_{C}^{*}$ value was used and only the fitting constants were recalculated for each region [4]. The latter case is known to under-predict creep life [38], and the former case, which more accurately describes the underlying physical processes $[37,39,40]$, was used by Whittaker and Wilshire to extrapolate the creep life of Grade 22, 23, and 24 steels [39]. In this study, both region-splitting techniques are used. Evans proposed a method to handle data from multiple batches [41], but this method requires a more complicated analysis that is outside the scope of this study, so it was not utilized.

\subsection{Larson-Miller Parameter Equation}

In the Larson-Miller parameter equation, the material constant $C$ is often set to 20 [12]. However, $C$ can be calculated if desired. The method described by Zhu et al. [42] was used to calculate $C$ in this work. The accuracy of Equation (8), the LMP fitting function, increases with the number of terms that are used. For this study, four terms were deemed to be sufficient so the parameters $B_{0}, B_{1}, B_{2}$ and $B_{3}$ 
were obtained. With this information, $t_{r}$ can be estimated for any given combination of temperature and stress.

Following the method detailed by Zhu et al. [42], the matrix laboratory software (MATLAB, version 2018b) surface fitting tool was used to determine the LMP equation constants. The Larson-Miller parameter equation was arranged as:

$$
z=\frac{B_{0}+B_{1} y+B_{2} y^{2}+B_{3} y^{3}}{x}-C
$$

where

$$
z=\log \left(t_{r}\right), x=T, y=\log (\sigma) \text {. }
$$

\section{Results and Discussion}

4.1. Investigation of Multiple Methods to Determine $Q_{C}^{*}$, Region-Splitting, the Use of Heat-and Processing-Specific Tensile Strength Values, and the Use of Short-Term Creep Rupture Data to Extrapolate Creep Life

Creep rupture data for Inconel 617 and Nimonic 105 were split into two data sets for each alloy; one consisted of all data, while the other was limited to data with rupture times less than 10,000 h. The purpose of the limited data set is to show the efficacy of extrapolating short-term test data to longer times, as it has been claimed that the Wilshire equation is well-suited to do so $[4,5,25,27,28,33]$. For each data set, values of $Q_{C}^{*}$ were determined using Arrhenius plots (shown in Tables 1 and 2), by optimizing the correlation of data on Wilshire plots (shown in Tables 3 and 4), and using the activation energy of self-diffusion of nickel in a nickel lattice, $292 \mathrm{~kJ} / \mathrm{mol}$ [43]. Since tensile strength values for each heat and processing condition are available for Nimonic 105, the effect of their use compared to the use of average values was investigated. Average tensile strength values were determined at each temperature using tensile strength values of all heats and processing conditions. Wilshire plots for each case were generated to show the goodness of fit of the data. To improve the goodness of fit, Wilshire plots for Inconel 617 were split into two regions: $\sigma<\sigma_{Y S}$ and $\sigma \geq \sigma_{Y S}$. Wilshire plots for Nimonic 105 were not split into regions because no data points have an applied stress higher than yield strength and no visible break appears in the data. For Inconel 617, negative $Q_{C}^{*}$ values were calculated using Arrhenius plots at two stress ratios, 0.4 and 0.5 , for data with an applied stress less than yield strength. These negative $Q_{C}^{*}$ values were omitted from average $Q_{C}^{*}$ calculations. Representative Wilshire plots are shown in Figure 1. Plots of all cases are provided as Figures A1-A5 in Appendix A. For both alloys, $Q_{C}^{*}$ values much lower than the activation energy of self-diffusion of nickel in a nickel lattice were occasionally obtained. Similarly, low $Q_{C}^{*}$ values have been obtained by others $[33,35,44]$.

\begin{tabular}{|c|c|c|c|c|c|c|c|c|c|c|c|}
\hline \multirow{2}{*}{ Data Set } & \multirow{2}{*}{$\begin{array}{l}\text { Stress } \\
\text { Region }\end{array}$} & \multirow{2}{*}{$\begin{array}{c}\text { Average } \\
Q_{C}^{*}\end{array}$} & \multicolumn{9}{|c|}{$\sigma / \sigma_{T S}$} \\
\hline & & & 0.1 & 0.2 & 0.3 & 0.4 & 0.5 & 0.6 & 0.7 & 0.8 & 0.9 \\
\hline \multirow{3}{*}{ All Data } & $\operatorname{All} \sigma$ & 190 & 63 & 122 & 118 & 193 & 252 & 362 & 173 & 28 & 401 \\
\hline & $\sigma<\sigma_{Y S}$ & 110 & 72 & 152 & 108 & $-12^{a}$ & $-154^{a}$ & - & - & - & - \\
\hline & $\sigma \geq \sigma_{Y S}$ & 285 & - & - & - & 530 & 318 & 274 & 161 & 28 & 401 \\
\hline \multirow{3}{*}{$t_{r}<10,000 \mathrm{~h}$} & All $\sigma$ & 162 & 50 & 60 & 106 & 157 & 227 & 307 & 151 & 26 & 376 \\
\hline & $\sigma<\sigma_{Y S}$ & 62 & 45 & 68 & 73 & $-6^{a}$ & $-132^{a}$ & - & - & - & - \\
\hline & $\sigma \geq \sigma_{Y S}$ & 254 & - & - & - & 413 & 285 & 278 & 148 & 26 & 376 \\
\hline
\end{tabular}

Table 1. Inconel $617 Q_{C}^{*}$ values $(\mathrm{kJ} / \mathrm{mol})$ determined using Arrhenius plots.

${ }^{\text {a }}$ Omitted from average $Q_{C}^{*}$ calculation. 
Table 2. Nimonic $105 Q_{C}^{*}$ values $(\mathrm{kJ} / \mathrm{mol})$ determined using Arrhenius plots.

\begin{tabular}{ccccc}
\hline \multirow{2}{*}{ Data Set } & \multirow{2}{*}{ Tensile Strength } & \multirow{2}{*}{ Average $Q_{C}^{*}$} & \multicolumn{2}{c}{$\sigma / \sigma_{T S}$} \\
\cline { 4 - 5 } & & & $\mathbf{0 . 2}$ & $\mathbf{0 . 3}$ \\
\hline \multirow{2}{*}{ All Data } & Average & 284 & 372 & 196 \\
& Heat- and processing-specific & 283 & 311 & 255 \\
\hline \multirow{2}{*}{$t_{r}<10,000 \mathrm{~h}$} & Average & 150 & - & 150 \\
& Heat- and processing-specific & 207 & - & 207 \\
\hline
\end{tabular}

Table 3. Inconel $617 Q_{C}^{*}$ values $(\mathrm{kJ} / \mathrm{mol})$ determined using Arrhenius plots.

\begin{tabular}{ccc}
\hline Data Set & Tensile Strength & $Q_{C}^{*}$ \\
\hline \multirow{3}{*}{ All Data } & All $\sigma$ & 224 \\
& $\sigma<\sigma_{Y S}$ & 109 \\
& $\sigma \geq \sigma_{Y S}$ & 266 \\
\hline \multirow{3}{*}{$t_{r}<10,000 \mathrm{~h}$} & All $\sigma$ & 202 \\
& $\sigma<\sigma_{Y S}$ & 90 \\
& $\sigma \geq \sigma_{Y S}$ & 235 \\
\hline
\end{tabular}

Table 4. Nimonic $105 Q_{C}^{*}$ values $(\mathrm{kJ} / \mathrm{mol})$ determined by optimizing the correlation of data on Wilshire plots.

\begin{tabular}{ccc}
\hline Data Set & Tensile Strength & $Q_{C}^{*}$ \\
\hline \multirow{2}{*}{ All Data } & Average & 289 \\
& Heat- and processing-specific & 272 \\
\hline \multirow{2}{*}{$t_{r}<10,000 \mathrm{~h}$} & Average & 196 \\
& Heat- and processing-specific & 235 \\
\hline
\end{tabular}

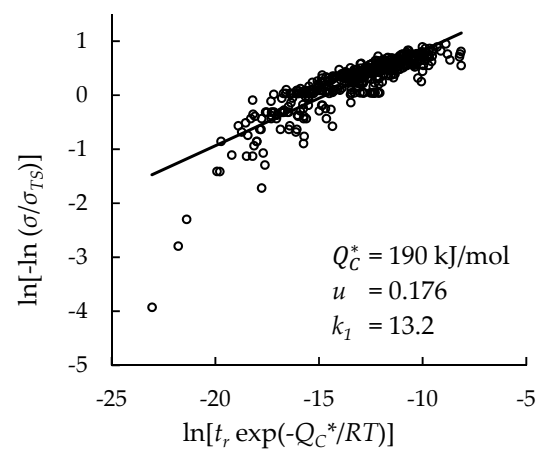

(a)

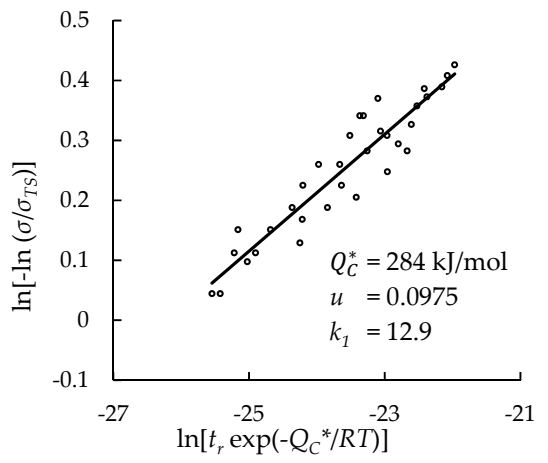

(c)

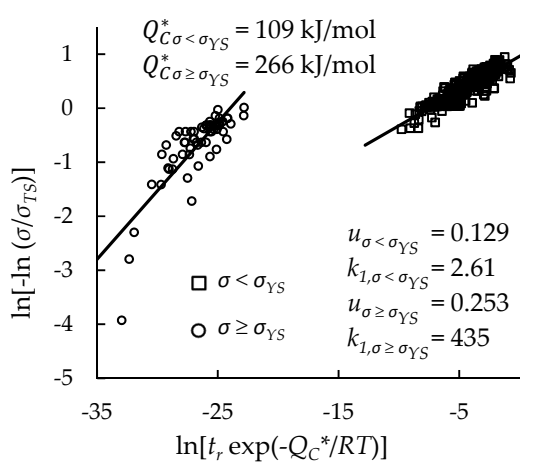

(b)

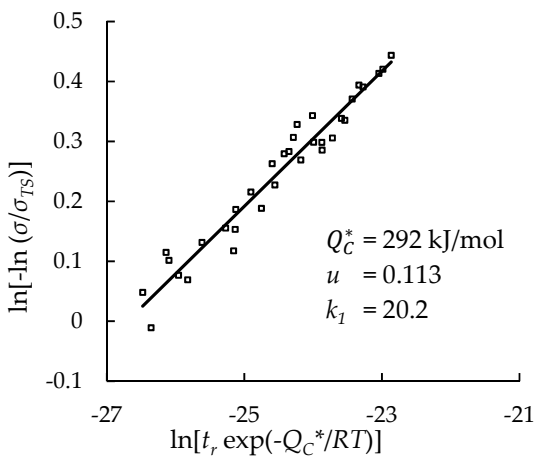

(d)

Figure 1. Goodness of fit of creep rupture data on Wilshire plots for: (a) Inconel 617 data treated as a single region; (b) Inconel 617 data split into above- and below-yield stress regions; (c) Nimonic 105 data with averaged tensile strength values; and (d) Nimonic 105 data with heat- and processing-specific tensile strength values. 
For all cases, time to rupture was calculated at the stress and temperature of each experimental data point. The error of the calculated rupture times in hours was measured using mean squared error (MSE), defined as

$$
\text { MSE }=\frac{\sum_{i=1}^{n}\left(t_{r, \text { calculated }, i}-t_{r, \text { experimental }, i}\right)^{2}}{n} .
$$

The Wilshire equation's goodness of fit (quantified by $\mathrm{R}^{2}$ ) for each data set and error obtained by applying the calculated $Q_{C}^{*}$ values and fitting constants to all creep rupture data are presented in Tables 5 and 6.

Table 5. Quality of fit and error for Inconel 617.

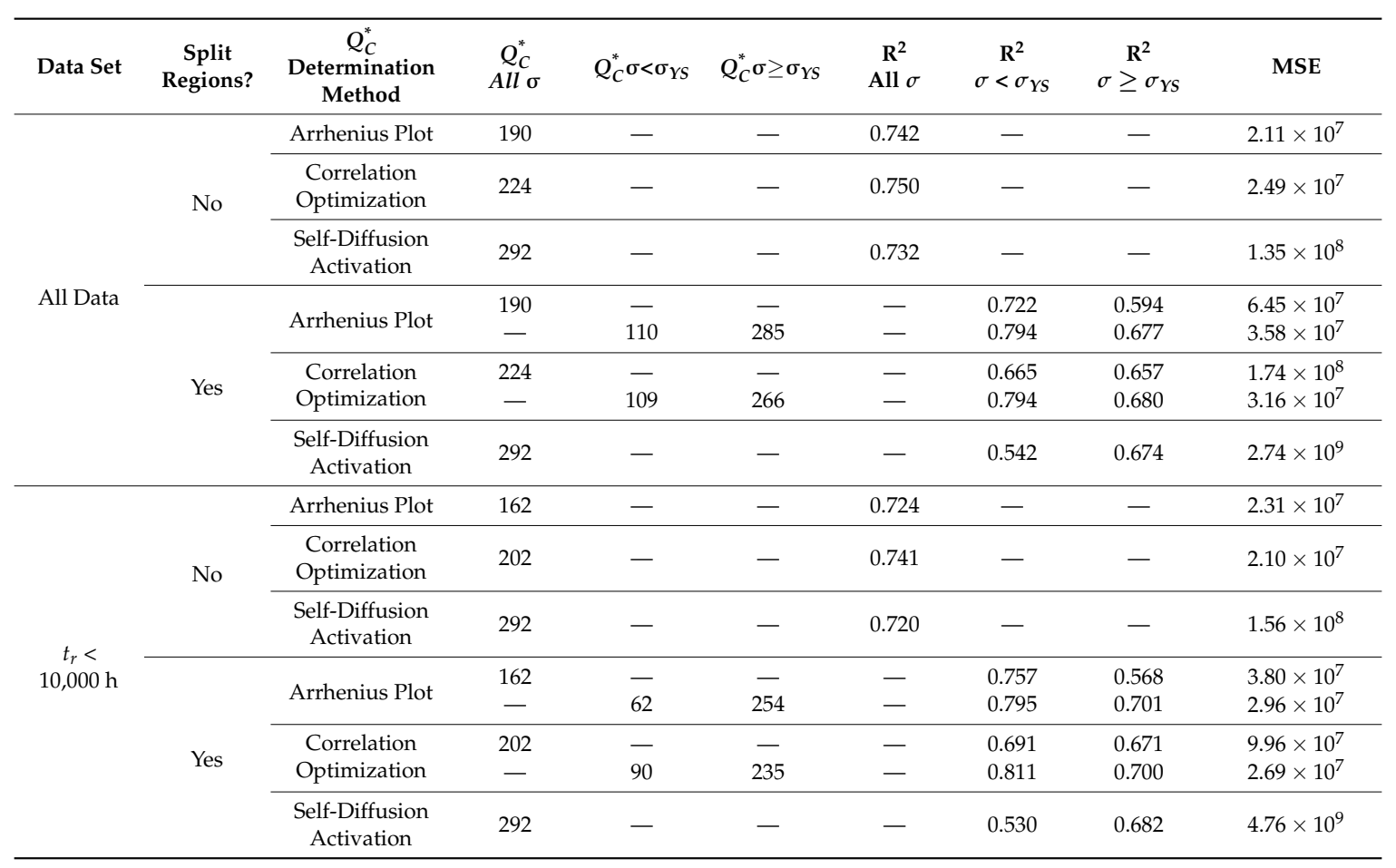

Table 6. Quality of fit and error for Nimonic 105.

\begin{tabular}{|c|c|c|c|c|c|}
\hline Data Set & Tensile Strength & $Q_{C}^{*}$ Determination Method & $\begin{array}{c}Q_{C}^{*} \\
\text { All } \sigma\end{array}$ & $\begin{array}{c}\mathbf{R}^{2} \\
\text { All } \sigma\end{array}$ & MSE \\
\hline \multirow{6}{*}{ All Data } & \multirow{3}{*}{ Average } & Arrhenius Plot & 284 & 0.880 & $2.00 \times 10^{7}$ \\
\hline & & Correlation Optimization & 289 & 0.880 & $2.01 \times 10^{7}$ \\
\hline & & Self-Diffusion Activation & 292 & 0.880 & $2.02 \times 10^{7}$ \\
\hline & \multirow{3}{*}{$\begin{array}{c}\text { Heat- and } \\
\text { processing-specific }\end{array}$} & Arrhenius Plot & 283 & 0.950 & $5.71 \times 10^{6}$ \\
\hline & & Correlation Optimization & 272 & 0.950 & $5.96 \times 10^{6}$ \\
\hline & & Self-Diffusion Activation & 292 & 0.949 & $5.58 \times 10^{6}$ \\
\hline \multirow{6}{*}{$t_{r}<10,000 \mathrm{~h}$} & \multirow{3}{*}{ Average } & Arrhenius Plot & 150 & 0.849 & $3.24 \times 10^{7}$ \\
\hline & & Correlation Optimization & 196 & 0.854 & $2.86 \times 10^{7}$ \\
\hline & & Self-Diffusion Activation & 292 & 0.838 & $2.02 \times 10^{7}$ \\
\hline & \multirow{3}{*}{$\begin{array}{c}\text { Heat- and } \\
\text { processing-specific }\end{array}$} & Arrhenius Plot & 207 & 0.879 & $1.98 \times 10^{7}$ \\
\hline & & Correlation Optimization & 235 & 0.880 & $1.81 \times 10^{7}$ \\
\hline & & Self-Diffusion Activation & 292 & 0.875 & $1.67 \times 10^{7}$ \\
\hline
\end{tabular}

For Inconel 617, the activation energy of self-diffusion of nickel in a nickel lattice gave the worst goodness of fit and error in all cases. Creep activation energy values at stresses below yield strength are much lower than those above yield strength. Both methods calculated much lower $Q_{C}^{*}$ values, 
ranging from 62 to $110 \mathrm{~kJ} / \mathrm{mol}$, than the published activation energy of self-diffusion of nickel in a nickel lattice, $292 \mathrm{~kJ} / \mathrm{mol}$. For data with an applied stress above yield strength, the calculated $Q_{C}^{*}$ values are slightly lower, but still near the activation energy of self-diffusion of nickel in a nickel lattice. Contrary to expectations, region splitting worsened the error in all cases. Additionally, using data with rupture times less than $10,000 \mathrm{~h}$ to calculate $Q_{C}^{*}$ and the fitting constants yielded errors similar to using all data. Regardless of the method used to calculate $Q_{C}^{*}$, relatively poor fits of the Wilshire equation to the Inconel 617 data were obtained. A similar issue of large data scatter of Inconel 617 has been reported by others [45,46].

For Nimonic 105, the goodness of fit and error improved dramatically from the use of heat- and processing-specific tensile strength values; for the data set with all data, the coefficient of determination increased from 0.88 to 0.95 and the mean squared error was reduced by about $70 \%$. All three methods to determine $Q_{C}^{*}$ gave a similar goodness of fit and error with all data. Compared to using all data, the calculated $Q_{C}^{*}$ values are much lower and the goodness of fit is worse when using data with rupture times less than $10,000 \mathrm{~h}$.

Figure 2 shows the correlation of the Wilshire equation and error at each potential value of $Q_{C}^{*}$, which were obtained when using the correlation optimization method to determine $Q_{C}^{*}$.

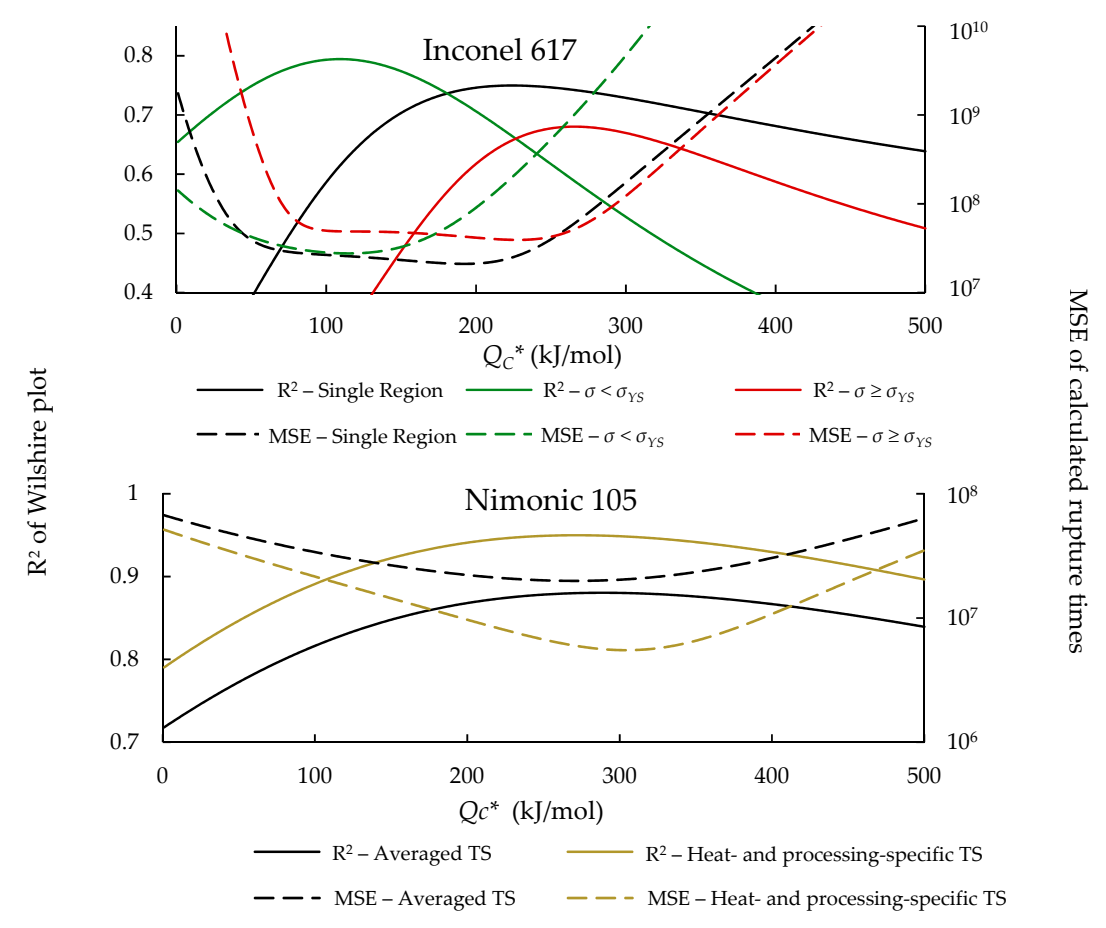

Figure 2. $R^{2}$ and MSE vs. $Q_{C}^{*}$ for all data.

The calculations of the Wilshire equation were plotted as stress vs. time to rupture. Plots for the method that provided the lowest error for each case are shown in Figures 3-6, while the remaining plots are shown in Figures A6-A19 in Appendix A. For ease of displaying calculations for Nimonic 105 using heat- and processing-specific tensile strength values, the $y$ axis of Figure 6 is shown as stress normalized by tensile strength. Calculated times to rupture for each data point and method to determine $Q_{C}^{*}$ for Nimonic 105 are shown in Table A2 in Appendix A. When splitting the data into above- and below-yield stress regions, the time to rupture at the transition from one region to the other is not calculated to be the same value in each region. Due to this, the split-region calculations of the Wilshire equation can yield zero or two stress values at some rupture times. The Inconel 617 plots show the tendency of the single-region rupture stress calculations to become more conservative than the split-region calculations as time increases. 


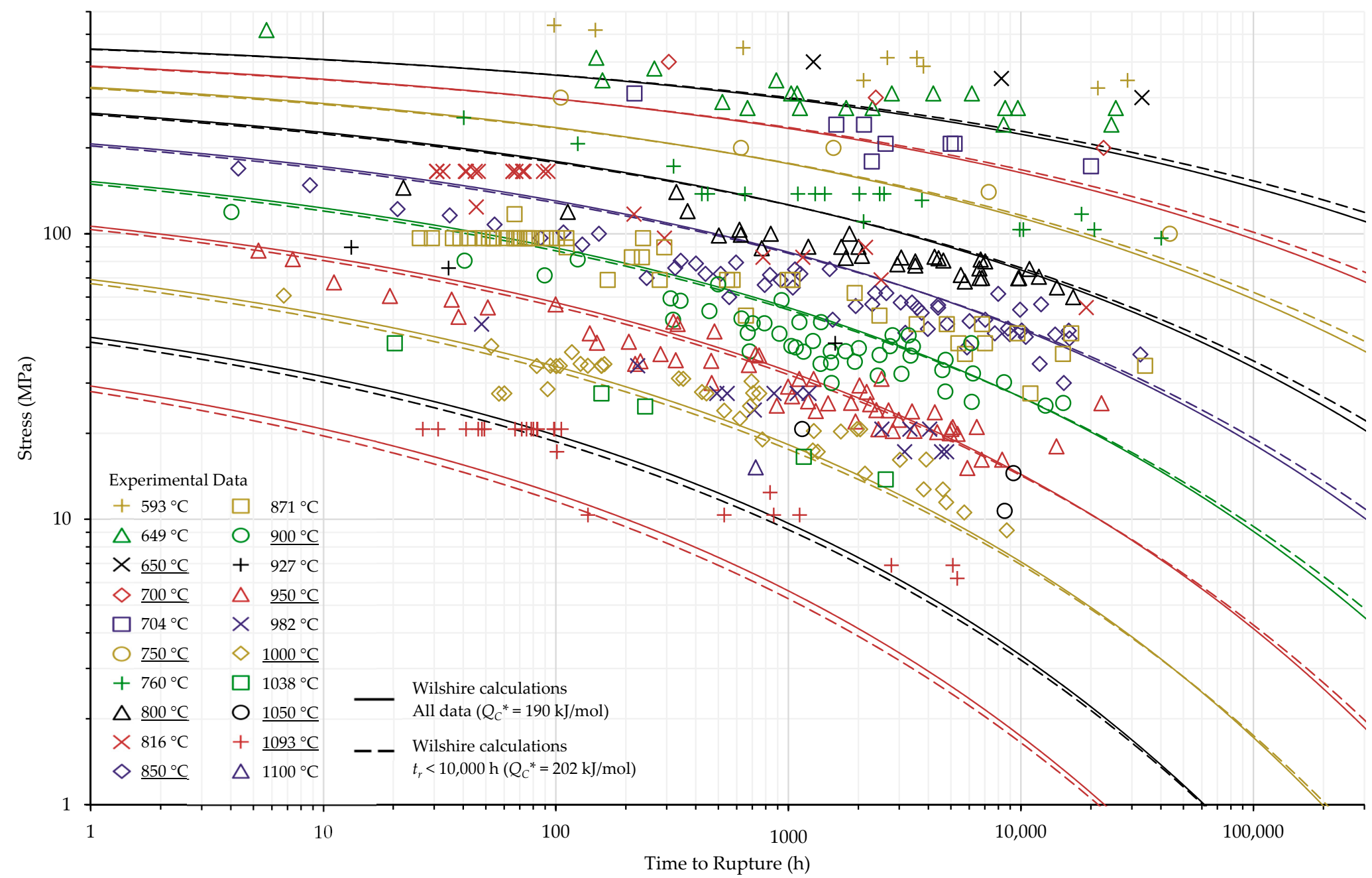

Figure 3. Single region calculations of the Wilshire equation with the lowest error for Inconel 617 shown at underlined temperatures. 


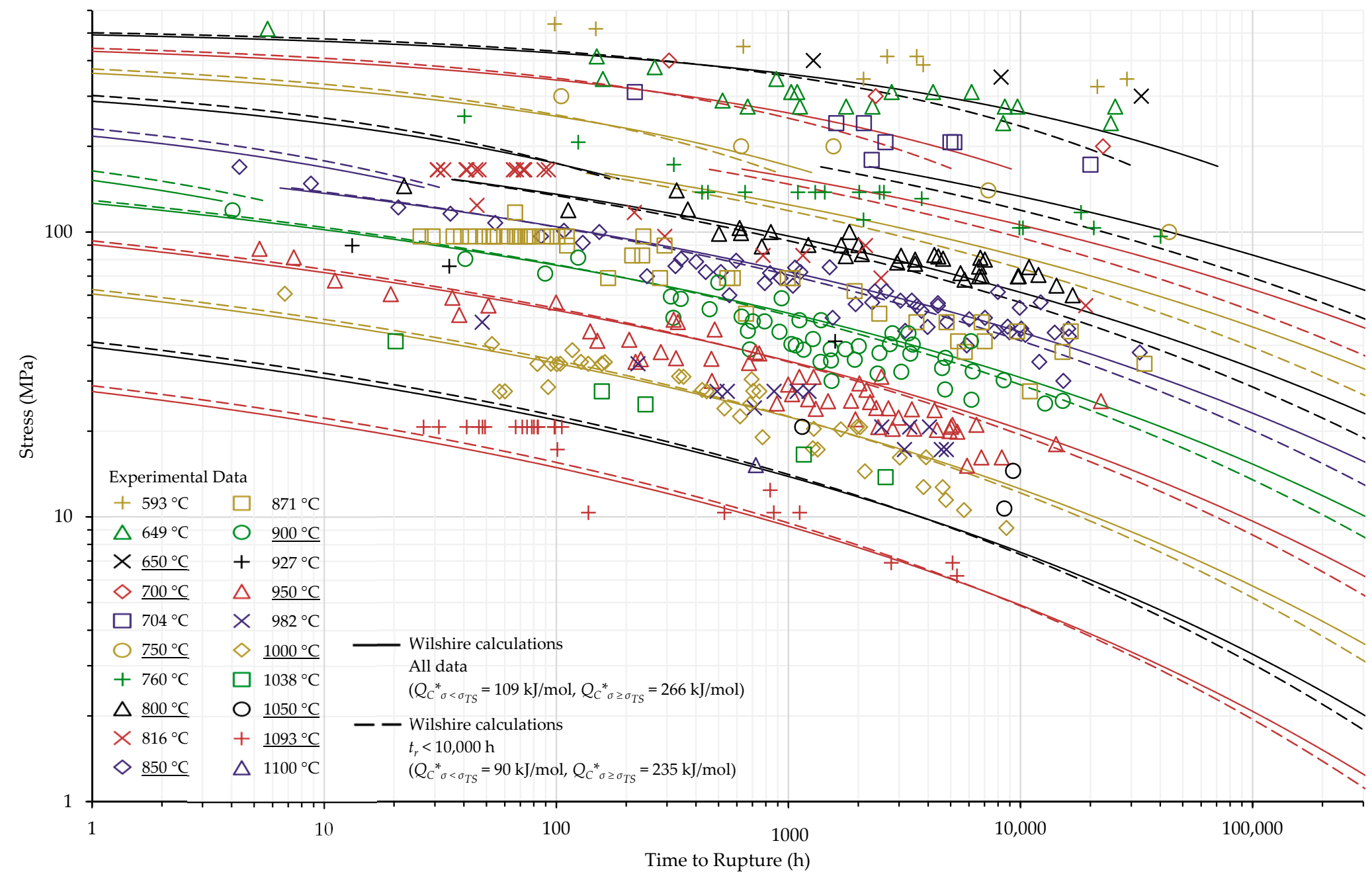

Figure 4. Split region calculations of the Wilshire equation with the lowest error for Inconel 617 shown at underlined temperatures. 


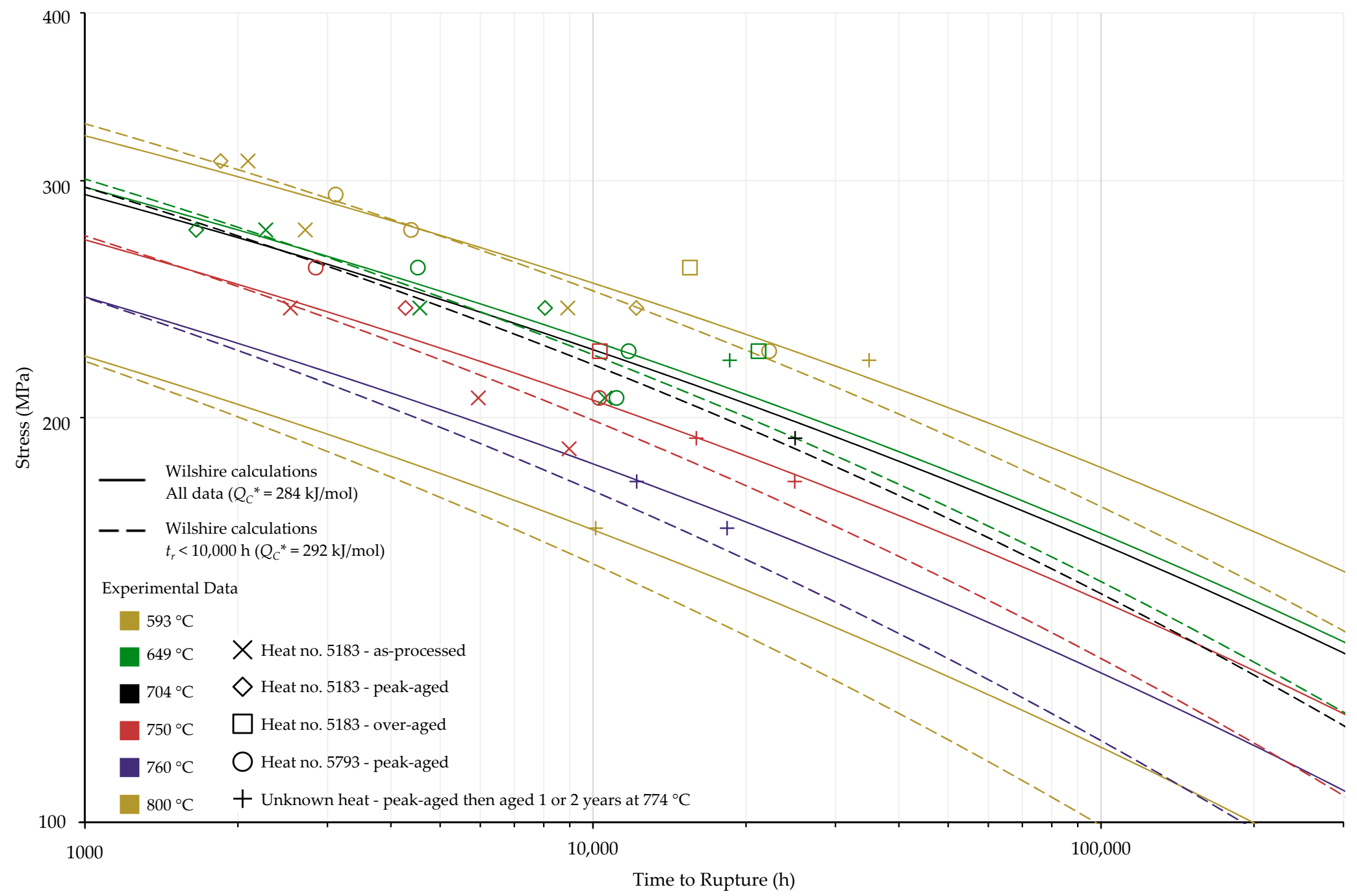

Figure 5. Calculations of the Wilshire equation with the lowest error for Nimonic 105 using averaged tensile strength values. 


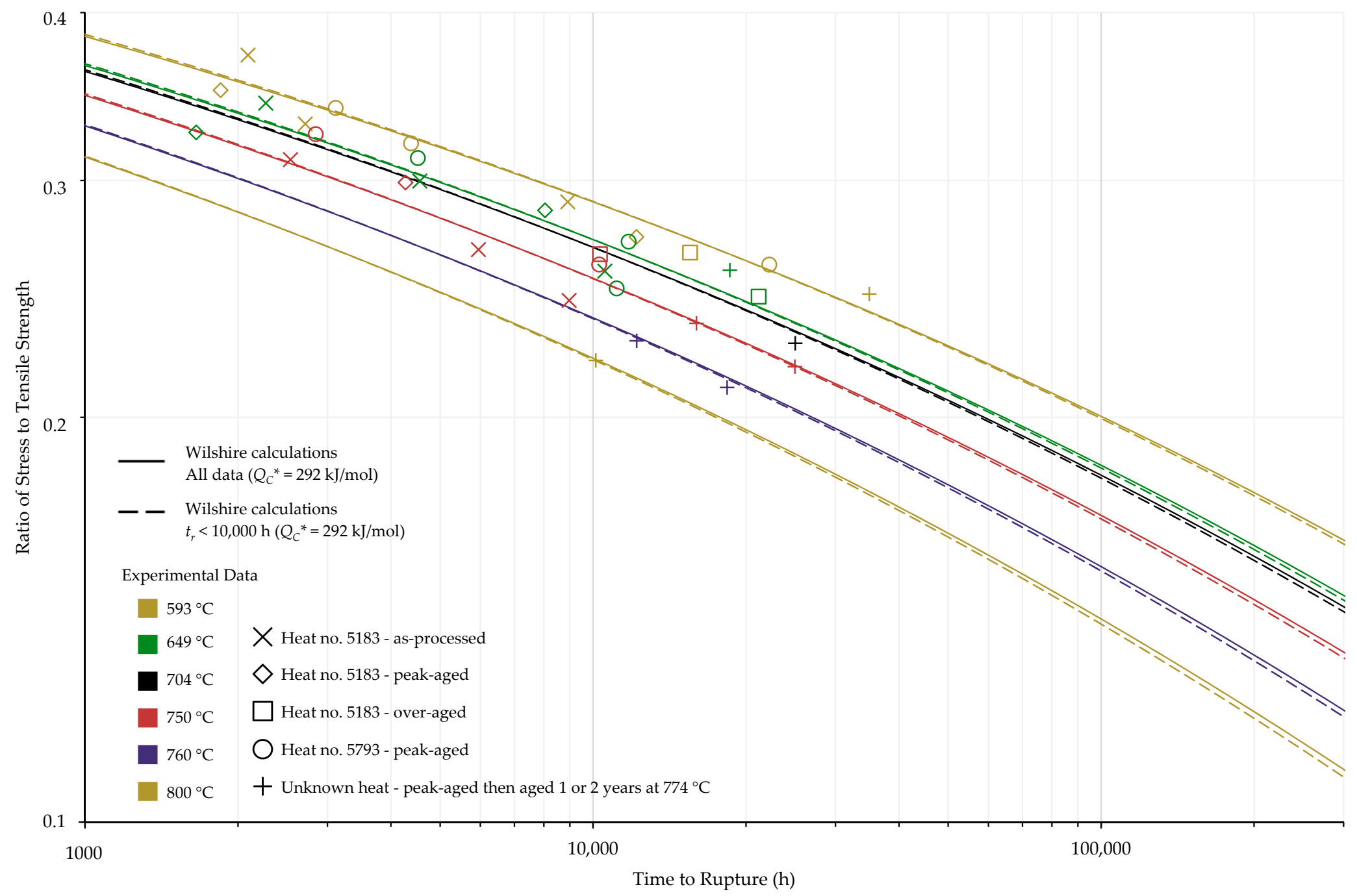

Figure 6. Calculations of the Wilshire equation with the lowest error for Nimonic 105 using heat- and processing-specific tensile strength values. 
From an engineering perspective, determining the average percentage difference between the calculated and experimentally-obtained rupture times is a reasonable way to show the tendency of the Wilshire equation to over- or under-predict creep life. For use by boiler pressure vessel design code organizations it is desirable that conservative estimations of creep life are produced. Average percentage difference is defined as

$$
\text { Average Percentage Difference }=\frac{\sum_{i=1}^{n}\left(\frac{t_{r, \text { calculated }, i}-t_{r, e x p e r i m e n t a l, i}}{t_{r, e x p e r i m e n t a l, i}}\right)}{n} \times 100 .
$$

For all cases, the average percentage difference was calculated at each temperature, and the results are shown in Figures 7-10.

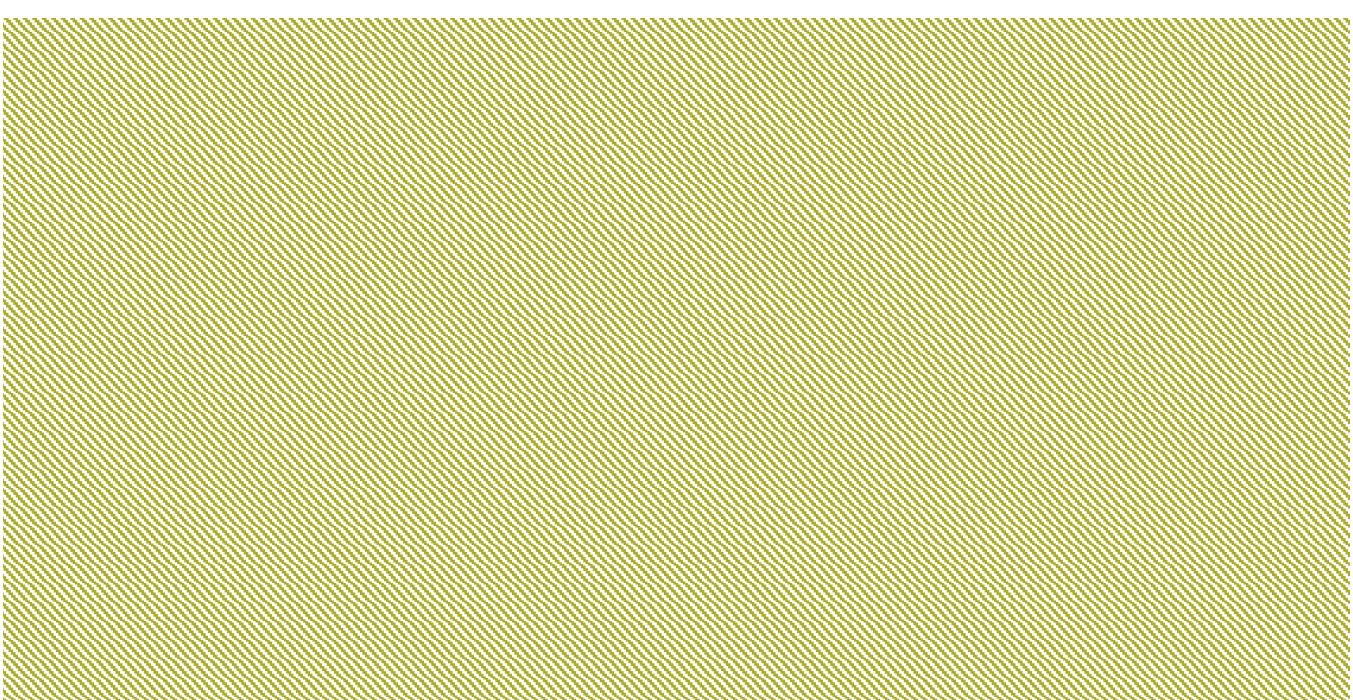

Figure 7. Average percentage difference at each temperature for Inconel 617 using all data to calculate $Q_{C}^{*}(\mathrm{~kJ} / \mathrm{mol})$.

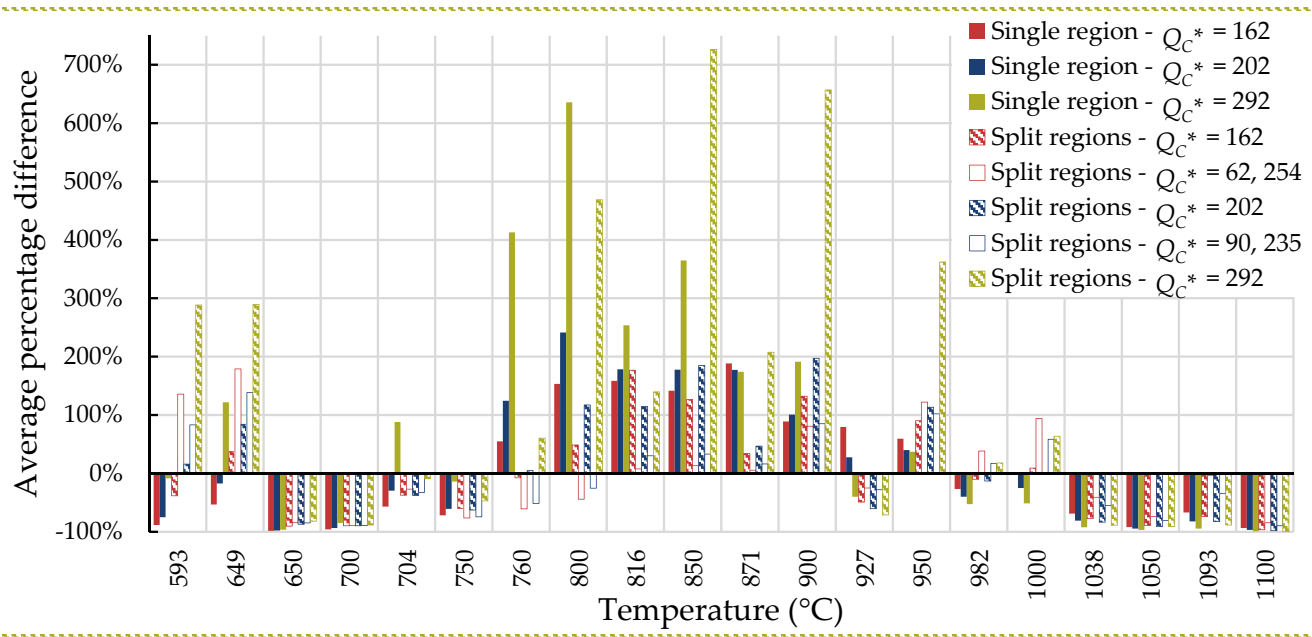

Figure 8. Average percentage difference at each temperature for Inconel 617 using data with times to rupture less than $10,000 \mathrm{~h}$ to calculate $Q_{C}^{*}(\mathrm{~kJ} / \mathrm{mol})$.

For Inconel 617 , calculations from 800 to $900{ }^{\circ} \mathrm{C}$ are generally not conservative and those beyond $1000{ }^{\circ} \mathrm{C}$ tend to be conservative regardless of the method used. Use of the self-diffusion activation energy of nickel in a nickel lattice as $Q_{C}^{*}$ gave the largest overpredictions of creep life for single- and split-region analyses. For Nimonic 105, the use of heat- and processing-specific tensile strength data usually—but not always-improved the average percentage difference. 


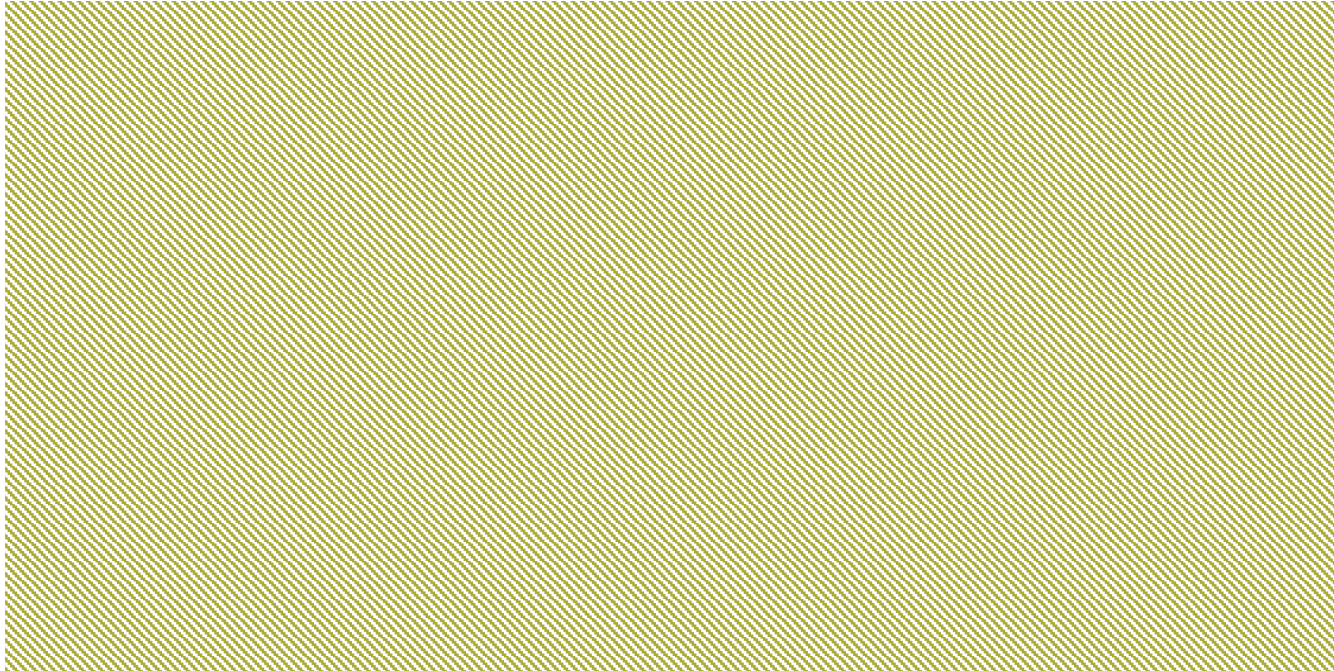

Figure 9. Average percentage difference at each temperature for Nimonic 105 using all data to calculate $Q_{C}^{*}(\mathrm{~kJ} / \mathrm{mol})$.

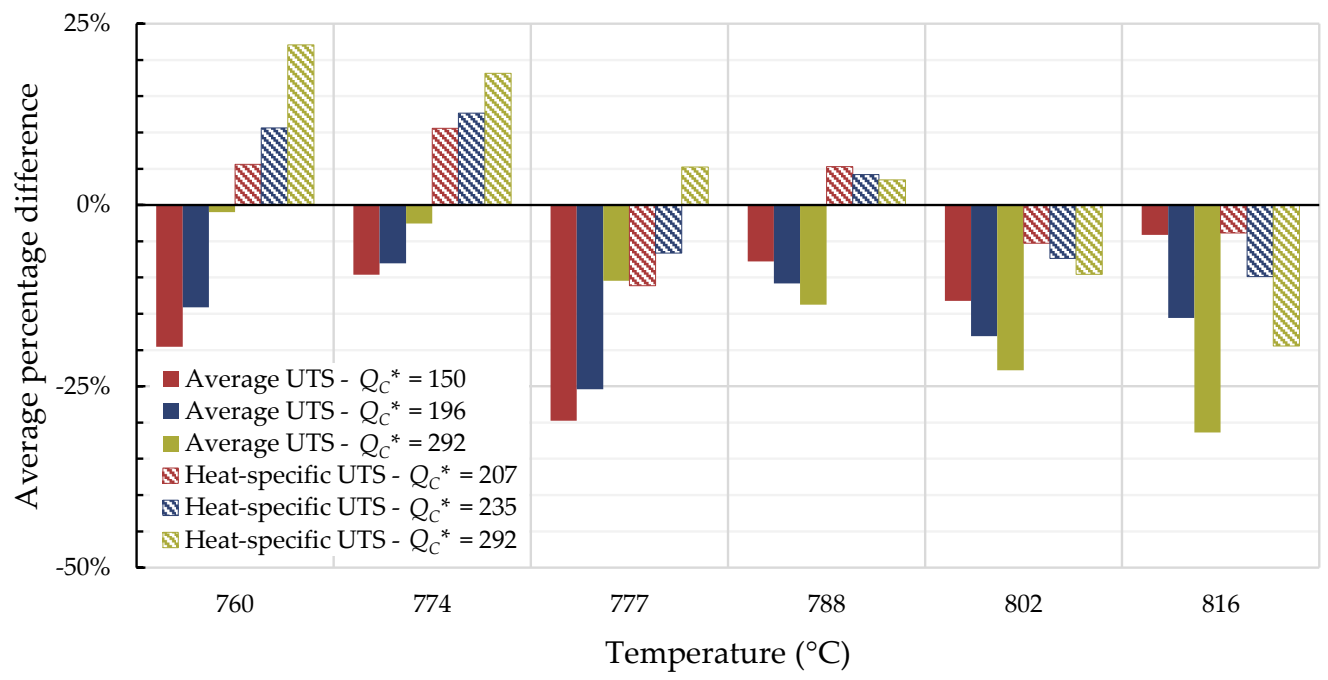

Figure 10. Average percentage difference at each temperature for Nimonic 105 using data with times to rupture less than $10,000 \mathrm{~h}$ to calculate $Q_{C}^{*}(\mathrm{~kJ} / \mathrm{mol})$.

The European Creep Collaborative Committee (ECCC) has extrapolated the creep life of various alloys to 100,000 h, including Inconel 617 [47]. As mentioned by Bullough, et al. [48], an interim Inconel 617B ECCC data sheet exists and a revision is in progress. A comparison of the creep strengths for rupture at 100,000 $\mathrm{h}$ specified by the ECCC and those obtained using the Wilshire equation are shown in Table 7 at temperatures that are common to both the ECCC's data sheet and the data used in this paper. The calculations of the Wilshire equation are closest to the values in the Inconel 617 ECCC data sheet when all data are treated as a single region and $Q_{C}^{*}$ is determined by optimizing the correlation of data on a Wilshire plot. Calculated creep strength values for rupture at 100,000 h for Nimonic 105 are presented in Table 8. For both alloys, the use of data with rupture times less than $10,000 \mathrm{~h}$ to calculate $Q_{C}^{*}$ generally resulted in lower calculated creep strengths for rupture at $100,000 \mathrm{~h}$. 
Table 7. Calculated creep strength for rupture of Inconel 617 at 100,000 h (MPa).

\begin{tabular}{|c|c|c|c|c|c|c|c|c|c|c|c|c|}
\hline Data Set & Split Regions? & $Q_{C}^{*}$ Determination Method & $Q_{C}^{*}$ All $\sigma$ & $Q_{C}^{*} \sigma<\sigma_{Y S}$ & $Q_{C}^{*} \sigma \geq \sigma_{Y S}$ & $650\left({ }^{\circ} \mathrm{C}\right)$ & $700\left({ }^{\circ} \mathrm{C}\right)$ & $750\left({ }^{\circ} \mathrm{C}\right)$ & $760\left({ }^{\circ} \mathrm{C}\right)$ & $800\left({ }^{\circ} \mathrm{C}\right)$ & $850\left({ }^{\circ} \mathrm{C}\right)$ & $900\left({ }^{\circ} \mathrm{C}\right)$ \\
\hline \multirow{8}{*}{ All Data } & \multirow{3}{*}{ No } & Arrhenius Plot & 190 & - & - & 146 & 95.8 & 59.0 & 53.2 & 34.0 & 18.3 & 9.07 \\
\hline & & Correlation Optimization & 224 & - & - & 171 & 115 & 71.8 & 64.8 & 41.8 & 22.6 & 11.2 \\
\hline & & Self-Diffusion Activation & 292 & - & - & 210 & 146 & 94.5 & 86.0 & 57.1 & 32.0 & 16.4 \\
\hline & \multirow{5}{*}{ Yes } & \multirow{2}{*}{ Arrhenius Plot } & 190 & - & - & 131 & 96.1 & 67.9 & 63.1 & 46.3 & 30.3 & 18.8 \\
\hline & & & - & 110 & 285 & 83.6 & 63.3 & 46.6 & 43.8 & 33.4 & 23.2 & 15.3 \\
\hline & & \multirow{2}{*}{ Correlation Optimization } & 224 & - & - & 148 & 109 & 77.2 & 71.8 & 52.7 & 34.4 & 21.3 \\
\hline & & & - & 109 & 266 & 83.0 & 62.9 & 46.4 & 43.6 & 33.3 & 23.1 & 15.3 \\
\hline & & Self-Diffusion Activation & 292 & - & - & 173 & 128 & 92.5 & 86.3 & 64.2 & 42.7 & 26.8 \\
\hline \multirow{8}{*}{$\begin{array}{c}t_{r}< \\
10,000 \mathrm{~h}\end{array}$} & \multirow{3}{*}{ No } & Arrhenius Plot & 162 & - & - & 118 & 76.2 & 46.2 & 41.5 & 26.3 & 14.0 & 6.93 \\
\hline & & Correlation Optimization & 202 & - & - & 153 & 101 & 62.4 & 56.2 & 35.9 & 19.2 & 9.44 \\
\hline & & Self-Diffusion Activation & 292 & - & - & 210 & 146 & 95.4 & 86.9 & 58.0 & 32.7 & 16.9 \\
\hline & \multirow{5}{*}{ Yes } & \multirow{2}{*}{ Arrhenius Plot } & 162 & - & - & 114 & 83.9 & 59.5 & 55.3 & 40.7 & 26.9 & 16.8 \\
\hline & & & - & 62 & 254 & 54.7 & 43.6 & 34.0 & 32.2 & 25.8 & 19.0 & 13.4 \\
\hline & & \multirow{2}{*}{ Correlation Optimization } & 202 & - & - & 137 & 101 & 71.8 & 66.7 & 49.0 & 32.2 & 20.0 \\
\hline & & & - & 90 & 235 & 69.1 & 52.8 & 39.4 & 37.0 & 28.6 & 20.1 & 13.5 \\
\hline & & Self-Diffusion Activation & 292 & - & - & $\mathrm{N} / \mathrm{A}^{1}$ & 129 & 93.9 & 87.8 & 65.7 & 44.1 & 28.0 \\
\hline \multirow{2}{*}{\multicolumn{6}{|c|}{$\begin{array}{l}\text { ECCC Inconel } 617 \text { Data Sheet (Year: 2005) } \\
\text { CCC Interim Inconel 617B Data Sheet (Year: 2014) }\end{array}$}} & 179 & 112 & 68 & 62 & 41 & 24 & 14.9 \\
\hline & & & & & & 222 & 129 & 70.6 & 62.7 & 39.9 & - & - \\
\hline
\end{tabular}

${ }^{1}$ The Wilshire equation did not yield a creep strength for rupture at 100,000 $\mathrm{h}$ in either the above- or below-yield stress region calculations (see Figure A13). 
Table 8. Calculated creep strength for rupture of Nimonic 105 at 100,000 h (MPa).

\begin{tabular}{|c|c|c|c|c|c|c|c|c|c|c|}
\hline Data Set & $\begin{array}{l}\text { Tensile } \\
\text { Strength }\end{array}$ & $\begin{array}{c}Q_{C}^{*} \text { Determination } \\
\text { Method }\end{array}$ & $Q_{C}^{*}$ & $\begin{array}{l}\text { Heat and } \\
\text { Processing } \\
\text { Condition }\end{array}$ & $\begin{array}{l}760 \\
\left({ }^{\circ} \mathrm{C}\right)\end{array}$ & $\begin{array}{l}774 \\
\left({ }^{\circ} \mathrm{C}\right)\end{array}$ & $\begin{array}{l}777 \\
\left({ }^{\circ} \mathrm{C}\right)\end{array}$ & $\begin{array}{l}788 \\
\left({ }^{\circ} \mathrm{C}\right)\end{array}$ & $\begin{array}{l}802 \\
\left({ }^{\circ} \mathrm{C}\right)\end{array}$ & $\begin{array}{l}816 \\
\left({ }^{\circ} \mathrm{C}\right)\end{array}$ \\
\hline \multirow{18}{*}{ All Data } & \multirow{3}{*}{ Average } & Arrhenius Plot & 284 & - & 183 & 164 & 161 & 146 & 129 & 114 \\
\hline & & $\begin{array}{c}\text { Correlation } \\
\text { Optimization }\end{array}$ & 289 & - & 184 & 164 & 161 & 146 & 129 & 114 \\
\hline & & $\begin{array}{l}\text { Self-Diffusion } \\
\text { Activation }\end{array}$ & 292 & - & 184 & 164 & 161 & 146 & 129 & 113 \\
\hline & \multirow{15}{*}{$\begin{array}{l}\text { Heat- and } \\
\text { processing- } \\
\text { specific }\end{array}$} & \multirow{5}{*}{ Arrhenius Plot } & \multirow{5}{*}{283} & $5183 \mathrm{AP}$ & 166 & 148 & 144 & 131 & 116 & 102 \\
\hline & & & & 5183 PA & 176 & 155 & 151 & 136 & 119 & 103 \\
\hline & & & & $5183 \mathrm{OA}$ & 194 & 167 & 162 & 143 & 121 & 102 \\
\hline & & & & 5793 PA & 172 & 152 & 148 & 134 & 118 & 103 \\
\hline & & & & Unknown PA $^{1}$ & 178 & 157 & 153 & 139 & 122 & 106 \\
\hline & & \multirow{5}{*}{$\begin{array}{l}\text { Correlation } \\
\text { Optimization }\end{array}$} & \multirow{5}{*}{272} & $5183 \mathrm{AP}$ & 165 & 147 & 143 & 130 & 115 & 102 \\
\hline & & & & $5183 \mathrm{PA}$ & 175 & 154 & 150 & 136 & 119 & 103 \\
\hline & & & & $5183 \mathrm{OA}$ & 193 & 166 & 161 & 142 & 121 & 102 \\
\hline & & & & 5793 PA & 170 & 151 & 148 & 134 & 118 & 104 \\
\hline & & & & Unknown PA ${ }^{1}$ & 176 & 156 & 153 & 138 & 122 & 107 \\
\hline & & \multirow{5}{*}{$\begin{array}{l}\text { Self-Diffusion } \\
\text { Activation }\end{array}$} & \multirow{5}{*}{292} & $5183 \mathrm{AP}$ & 167 & 148 & 145 & 131 & 116 & 102 \\
\hline & & & & 5183 PA & 177 & 156 & 152 & 136 & 119 & 103 \\
\hline & & & & $5183 \mathrm{OA}$ & 195 & 168 & 163 & 143 & 121 & 102 \\
\hline & & & & 5793 PA & 173 & 153 & 149 & 134 & 118 & 103 \\
\hline & & & & Unknown PA ${ }^{1}$ & 179 & 158 & 154 & 139 & 122 & 106 \\
\hline \multirow{18}{*}{$\begin{array}{c}t_{r}< \\
10,000 \mathrm{~h}\end{array}$} & \multirow{3}{*}{ Average } & Arrhenius Plot & 150 & - & 148 & 134 & 132 & 121 & 109 & 97 \\
\hline & & $\begin{array}{c}\text { Correlation } \\
\text { Optimization }\end{array}$ & 196 & - & 155 & 139 & 136 & 124 & 110 & 97 \\
\hline & & $\begin{array}{l}\text { Self-diffusion } \\
\text { Activation }\end{array}$ & 292 & - & 172 & 151 & 148 & 132 & 115 & 99 \\
\hline & \multirow{15}{*}{$\begin{array}{l}\text { Heat- and } \\
\text { processing- } \\
\text { specific }\end{array}$} & \multirow{5}{*}{ Arrhenius Plot } & \multirow{5}{*}{207} & $5183 \mathrm{AP}$ & 153 & 138 & 135 & 124 & 111 & 99 \\
\hline & & & & 5183 PA & 162 & 145 & 141 & 129 & 114 & 100 \\
\hline & & & & $5183 \mathrm{OA}$ & 179 & 156 & 151 & 135 & 116 & 99 \\
\hline & & & & 5793 PA & 158 & 142 & 139 & 127 & 113 & 101 \\
\hline & & & & Unknown PA ${ }^{1}$ & 164 & 147 & 143 & 131 & 117 & 103 \\
\hline & & \multirow{5}{*}{$\begin{array}{l}\text { Correlation } \\
\text { Optimization }\end{array}$} & \multirow{5}{*}{235} & $5183 \mathrm{AP}$ & 157 & 141 & 138 & 126 & 112 & 99 \\
\hline & & & & $5183 \mathrm{PA}$ & 167 & 148 & 144 & 131 & 115 & 101 \\
\hline & & & & $5183 \mathrm{OA}$ & 184 & 159 & 155 & 137 & 117 & 99 \\
\hline & & & & $5793 \mathrm{PA}$ & 163 & 145 & 142 & 129 & 114 & 101 \\
\hline & & & & Unknown PA ${ }^{1}$ & 168 & 150 & 146 & 133 & 118 & 104 \\
\hline & & \multirow{5}{*}{$\begin{array}{l}\text { Self-Diffusion } \\
\text { Activation }\end{array}$} & \multirow{5}{*}{292} & $5183 \mathrm{AP}$ & 166 & 147 & 144 & 130 & 115 & 101 \\
\hline & & & & $5183 \mathrm{PA}$ & 177 & 155 & 151 & 136 & 118 & 102 \\
\hline & & & & $5183 \mathrm{OA}$ & 194 & 167 & 162 & 142 & 120 & 101 \\
\hline & & & & 5793 PA & 172 & 152 & 148 & 134 & 117 & 102 \\
\hline & & & & Unknown PA ${ }^{1}$ & 178 & 157 & 153 & 138 & 121 & 105 \\
\hline
\end{tabular}

${ }^{1}$ Aged for $1-2$ years at $774{ }^{\circ} \mathrm{C}$.

\subsection{Comparison of Calculations of the Wilshire and Larson-Miller Parameter Equations}

The Larson-Miller parameter equation was used to provide calculations for comparison with the calculations of the Wilshire equation. Equation (9) and the MATLAB surface fitting tool were used to correlate the experimental data to the LMP equation and the resulting coefficients and goodness of fit are shown in Table 9.

Table 9. MATLAB calculations of the LMP coefficients and goodness of fit.

\begin{tabular}{ccccccc}
\hline Alloy & $\boldsymbol{B}_{0}$ & $\boldsymbol{B}_{1}$ & $\boldsymbol{B}_{2}$ & $\boldsymbol{B}_{3}$ & $\boldsymbol{C}$ & $\mathbf{R}^{\mathbf{2}}$ \\
\hline Inconel 617 & 32,630 & -8114 & 1749 & -357.2 & 16.02 & 0.837 \\
Nimonic 105 & 354,200 & $-426,900$ & 185,600 & $-27,280$ & 16.88 & 0.842 \\
\hline
\end{tabular}

Time to rupture was calculated at the stress and temperature of each experimental data point using the LMP equation. The mean squared error of the calculated rupture times is compared to the lowest error obtained using the Wilshire equation with all data in Table 10. The error of the Wilshire 
calculations is lower than that of the LMP equation for both alloys. The best goodness of fit was achieved with the LMP equation for Inconel 617 and with the Wilshire equation for Nimonic 105.

Table 10. Goodness of fit and error of Wilshire and LMP calculations.

\begin{tabular}{cccc}
\hline Alloy & Equation & $\mathbf{R}^{2}$ & MSE \\
\hline \multirow{2}{*}{ Inconel 617 } & LMP Equation & 0.837 & $2.69 \times 10^{7}$ \\
& Wilshire Equation $^{1}$ & 0.742 & $2.11 \times 10^{7}$ \\
\hline \multirow{2}{*}{ Nimonic 105 } & LMP Equation & 0.842 & $1.68 \times 10^{7}$ \\
& Wilshire Equation $^{2}$ & 0.949 & $5.58 \times 10^{6}$ \\
\hline
\end{tabular}

${ }^{1}$ Data treated as a single region with $Q_{C}^{*}$ calculated using Arrhenius plots; ${ }^{2}$ Heat- and processing-specific tensile strength data with the self-diffusion activation energy of nickel in a nickel lattice as $Q_{C}^{*}$.

A comparison of the tendency for each equation to over- or under-predict creep life-quantified as the average percentage difference between calculated and experimentally-obtained rupture times-is shown in Figures 11 and 12. For Inconel 617, the over- and under-predictions of the LMP equation are generally less severe than those of the Wilshire equation, except at the two lowest temperatures.

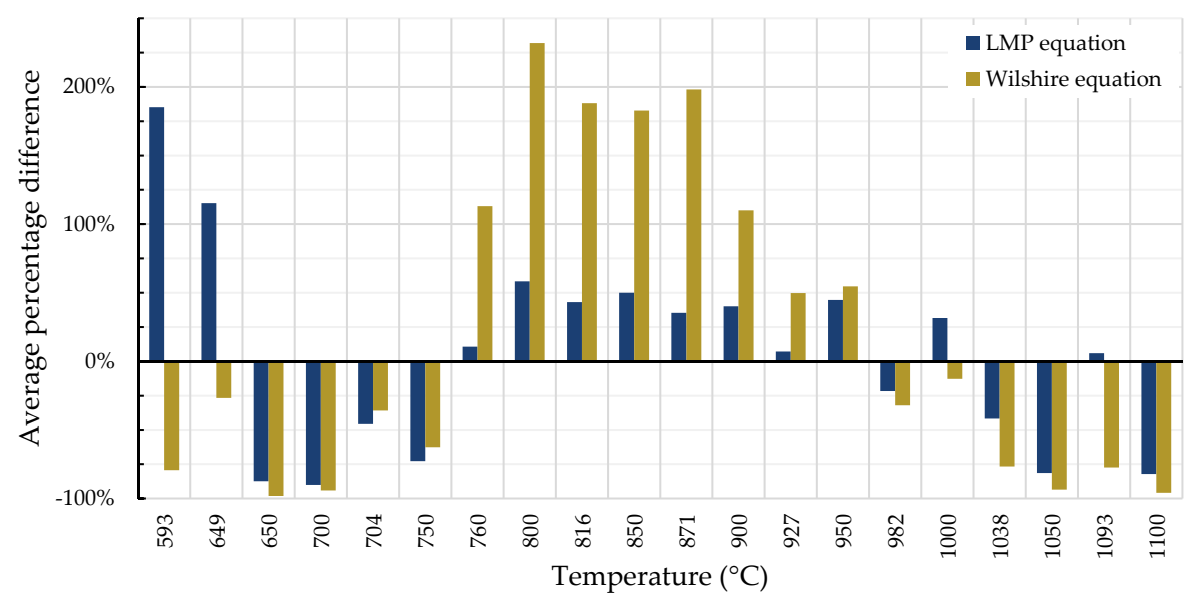

Figure 11. Average percentage difference of calculated and experimental rupture times for Inconel 617.

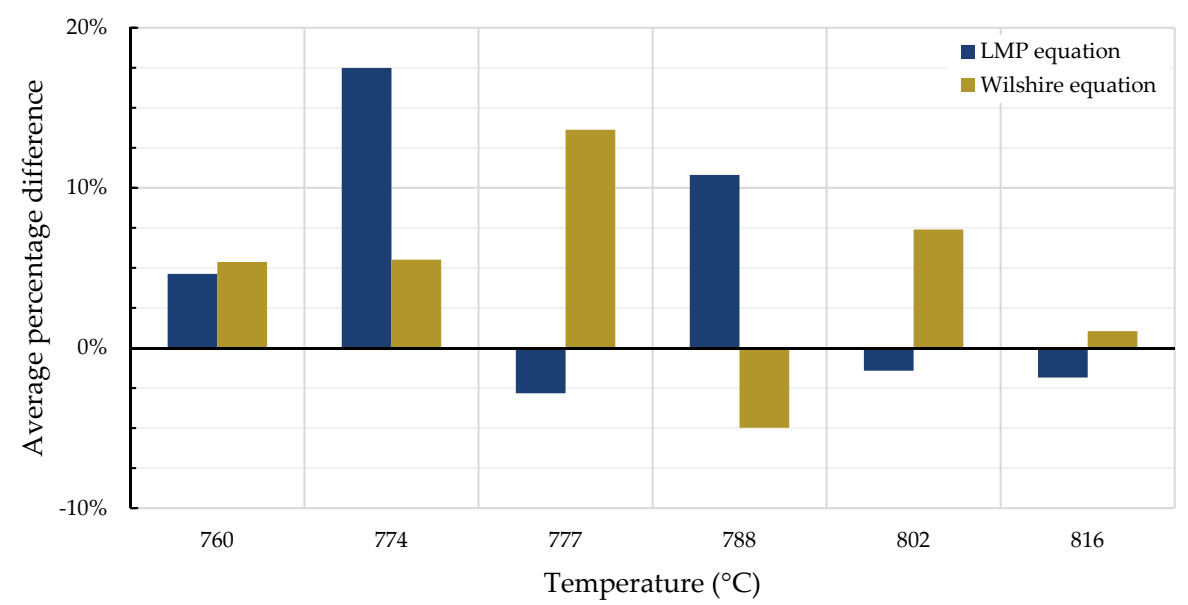

Figure 12. Average percentage difference of calculated and experimental rupture times for Nimonic 105.

The percentage differences of the calculated rupture time for the longest test duration of each alloy is defined as

$$
\text { Percentage Difference }=\frac{t_{r, \text { calculated }}-t_{r, \text { experimental }}}{t_{r, \text { experimental }}} \times 100
$$


As shown in Table 11 the calculated rupture time for both equations was conservative for each alloy compared to the longest experimental test data points. The LMP equation yielded more conservative estimates than the Wilshire equation.

Table 11. Percentage differences of the calculated rupture times for the longest test durations.

\begin{tabular}{|c|c|c|c|c|c|}
\hline \multirow{2}{*}{ Alloy } & \multirow{2}{*}{ Calculation Method } & \multirow{2}{*}{$\begin{array}{l}\text { Percentage } \\
\text { Difference }\end{array}$} & \multicolumn{3}{|c|}{ Experimental Values of Longest Test Duration } \\
\hline & & & Temperature $\left({ }^{\circ} \mathrm{C}\right)$ & Stress (MPa) & Time to Rupture (h) \\
\hline Inconel 617 & $\begin{array}{c}\text { LMP Equation } \\
\text { Wilshire Equation }{ }^{1}\end{array}$ & $\begin{array}{l}-73.8 \% \\
-61.0 \%\end{array}$ & 750 & 100 & 43,706 \\
\hline Nimonic 105 & $\begin{array}{c}\text { LMP Equation } \\
\text { Wilshire Equation } 2\end{array}$ & $\begin{array}{l}-31.2 \% \\
-17.2 \%\end{array}$ & 760 & 221 & 34,955 \\
\hline
\end{tabular}

${ }^{1}$ Data treated as a single region with $Q_{C}^{*}$ calculated using Arrhenius plots; ${ }^{2}$ Heat- and processing-specific tensile strength data with the self-diffusion activation energy of nickel in a nickel lattice as $Q_{C}^{*}$.

Calculated creep strengths for rupture at 100,000 h using the LMP and Wilshire equations are presented in Tables 12 and 13. Figures 13 and 14 show experimental creep data, calculations of the LMP equation, and calculations of the Wilshire equation using the $Q_{C}^{*}$ value that yielded the lowest error. For ease of displaying the calculations, the $y$ axis of Figure 14 is stress normalized by tensile strength, and the stresses calculated using the LMP equation are normalized by average tensile strength values. Calculated times to rupture for each data point and method to determine $Q_{C}^{*}$ for Nimonic 105 are shown in Table A2 in Appendix A. The form of the stress function used in the LMP equation can result in multiple values of stress to be calculated at a single rupture time; however, this issue was not observed for either data set. For Inconel 617, the calculations of the Wilshire equation are more conservative than those of the LMP equation at failure times approaching and beyond 100,000 h. Nimonic 105 exhibited the same behavior at 800 and $850{ }^{\circ} \mathrm{C}$. For Inconel 617 , both the Wilshire and LMP equations predicted 100,000 h creep strengths lower or only slightly higher than the values calculated by the ECCC, including the temperature range of 800 to $900{ }^{\circ} \mathrm{C}$ where both equations overpredicted creep life vs. the experimental data (see Figure 11).

Table 12. Calculated creep strength for rupture at 100,000 h (MPa) of Inconel 617.

\begin{tabular}{ccccccccc}
\hline Calculation Method & $\mathbf{6 5 0}{ }^{\circ} \mathbf{C}$ & $\mathbf{7 0 0}{ }^{\circ} \mathbf{C}$ & $\mathbf{7 5 0}{ }^{\circ} \mathbf{C}$ & $\mathbf{8 0 0}{ }^{\circ} \mathbf{C}$ & $\mathbf{8 5 0}{ }^{\circ} \mathbf{C}$ & $\mathbf{9 0 0}{ }^{\circ} \mathbf{C}$ & $\mathbf{9 5 0}^{\circ} \mathbf{C}$ & $\mathbf{1 0 0 0}^{\circ} \mathbf{C}$ \\
\hline LMP Equation & 161 & 104 & 66.0 & 41.7 & 26.4 & 16.8 & 10.8 & 7.13 \\
Wilshire Equation ${ }^{1}$ & 145 & 95.8 & 59.0 & 34.0 & 18.3 & 9.07 & 4.14 & 1.72 \\
ECCC (Year: 2005) & 179 & 112 & 68 & 41 & 24 & 14.9 & - & - \\
\hline
\end{tabular}

${ }^{1}$ Data treated as a single region with $Q_{C}^{*}$ calculated using Arrhenius plots.

Table 13. Calculated creep strength for rupture at 100,000 h (MPa) of Nimonic 105.

\begin{tabular}{|c|c|c|c|c|c|}
\hline $\begin{array}{l}\text { Calculation } \\
\text { Method }\end{array}$ & $\begin{array}{l}\text { Heat and Processing } \\
\text { Condition }\end{array}$ & $700^{\circ} \mathrm{C}$ & $750^{\circ} \mathrm{C}$ & $800^{\circ} \mathrm{C}$ & $850^{\circ} \mathrm{C}$ \\
\hline LMP Equation & - & 273 & 189 & 129 & 99.7 \\
\hline \multirow{5}{*}{$\begin{array}{l}\text { Wilshire } \\
\text { Equation }^{1}\end{array}$} & $5183 \mathrm{AP}$ & 270 & 182 & 117 & 72.5 \\
\hline & 5183 PA & 297 & 194 & 121 & 70.8 \\
\hline & $5183 \mathrm{OA}$ & 351 & 217 & 124 & 63.1 \\
\hline & 5793 PA & 282 & 188 & 120 & 72.7 \\
\hline & Unknown PA ${ }^{2}$ & 294 & 195 & 124 & 74.4 \\
\hline
\end{tabular}

${ }^{1}$ Heat- and processing-specific tensile strength data with the self-diffusion activation energy of nickel in a nickel lattice as $Q_{C}^{*} ;{ }^{2}$ Aged for $1-2$ years at $774{ }^{\circ} \mathrm{C}$. 


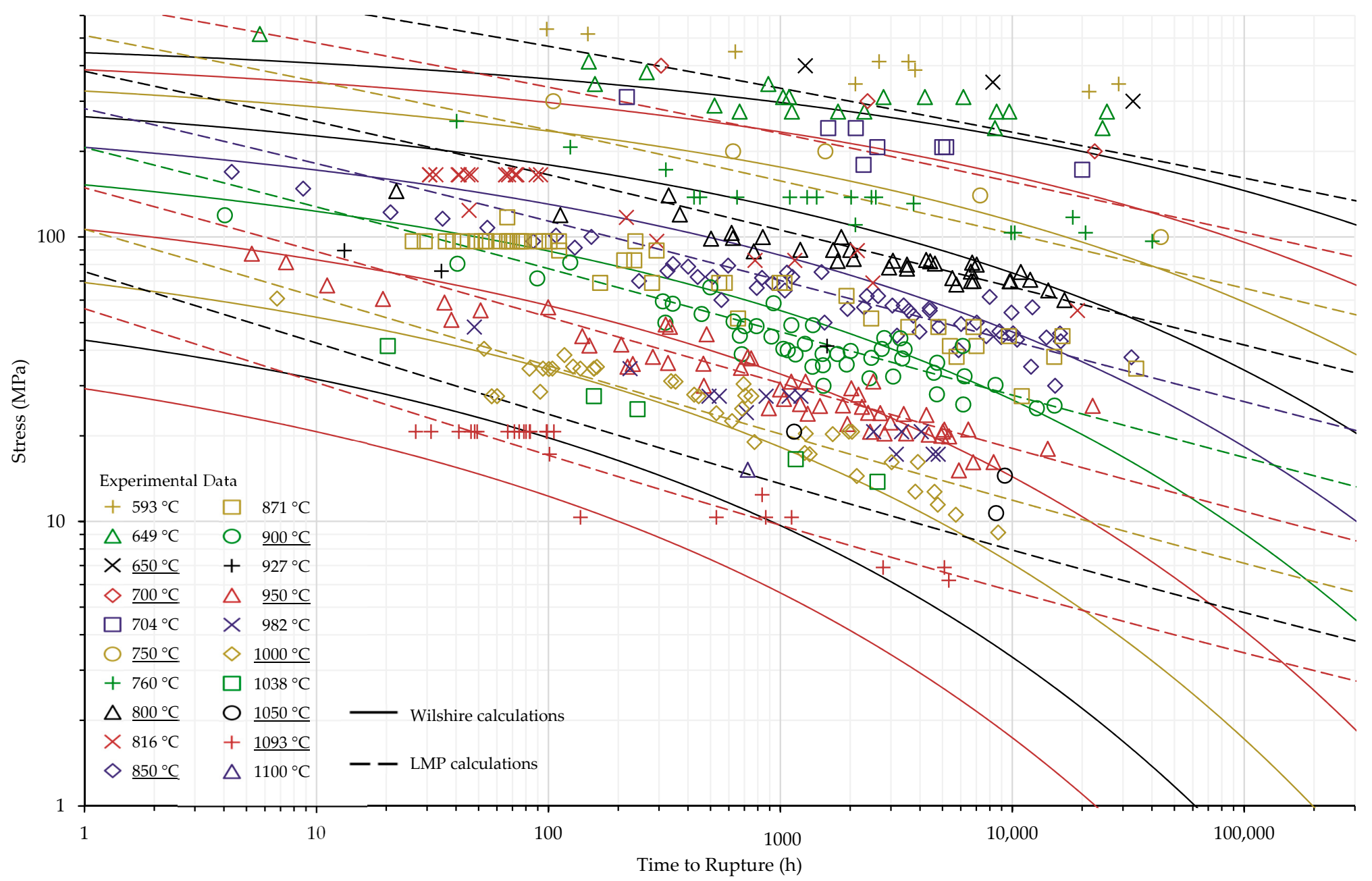

Figure 13. Calculated rupture times for Inconel 617 shown at underlined temperatures. 


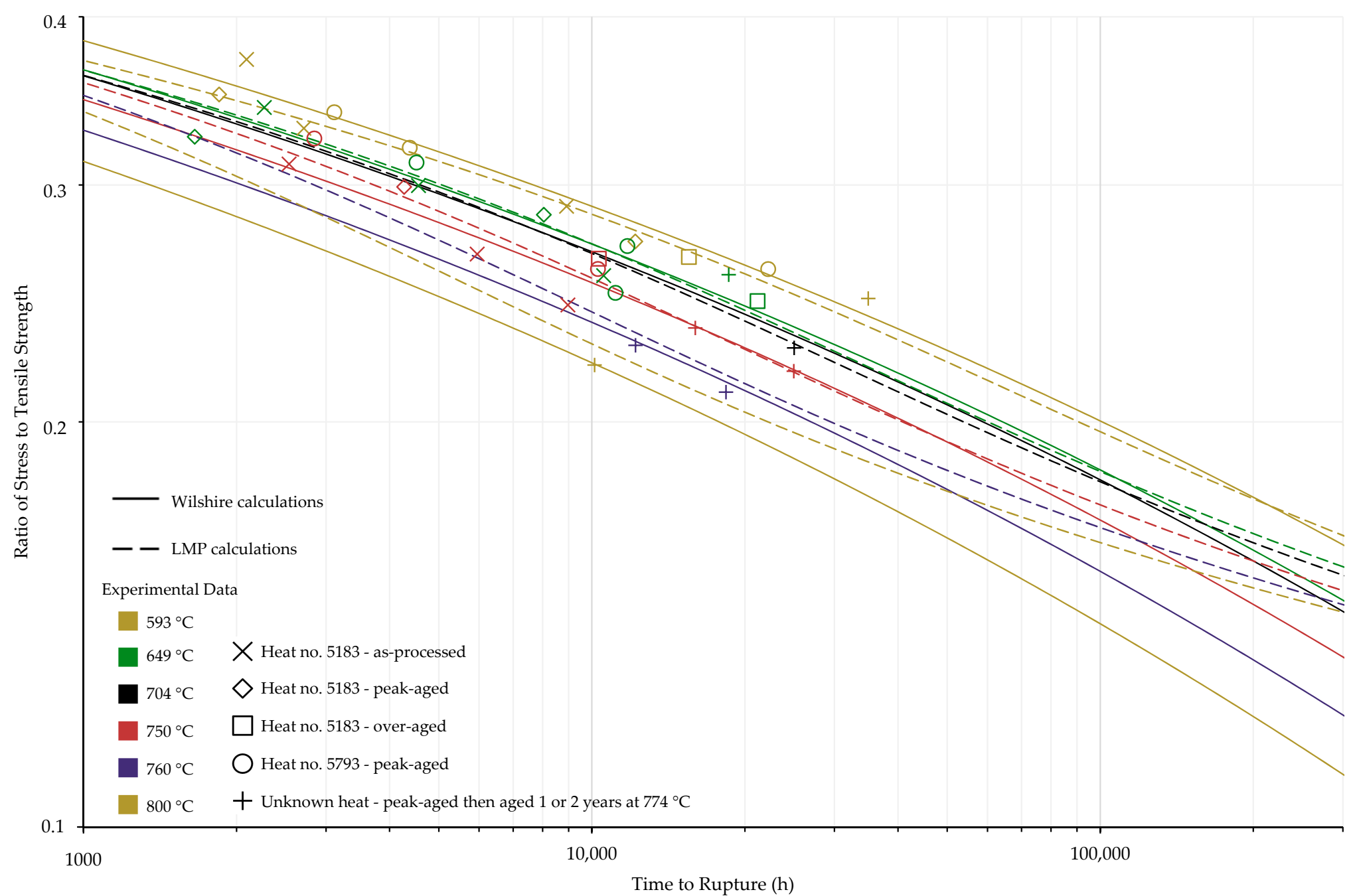

Figure 14. Calculated rupture times for Nimonic 105. 


\section{Conclusions}

This study investigated multiple methods to determine $Q_{C}^{*}$, the effect of region-splitting, the use of short-term creep rupture data to extrapolate creep life, and the use of heat- and processing-specific tensile strength values, all of which are techniques that have been used or proposed to increase the accuracy of the Wilshire equation.

The large temperature span of Inconel 617 data, over $500{ }^{\circ} \mathrm{C}$, may be the cause for relatively poor fits of both the Wilshire and LMP models to the data. At higher temperatures, greater than $850{ }^{\circ} \mathrm{C}$, microstructural changes that affect creep strength may be accelerated, or other strength degradation phenomena might become significant that do not occur at lower temperatures. For Inconel 617, the mean squared error of the calculated creep life using the self-diffusion activation energy of nickel in a nickel lattice as $Q_{C}^{*}$ was about an order of magnitude greater than the other methods to determine $Q_{C}^{*}$. The large scatter and temperature range may have exacerbated potential error introduced by using the self-diffusion activation energy as $Q_{C}^{*}$, rather than using a value calculated from the data. With the well-behaved Nimonic 105 data, a very similar goodness of fit was obtained using any of the three methods for determining $Q_{C}^{*}$. It is possible that calculations of the Wilshire equation are not significantly affected by the $Q_{C}^{*}$ value when a small data set with low scatter is used. If a high degree of fit to the data is required, the authors recommend that self-diffusion activation energy not be used as $Q_{C}^{*}$ due to the potential for large error, as seen for Inconel 617. Using the $Q_{C}^{*}$ value that provided the lowest error, the longest time to rupture for both alloys was underpredicted, which is much more desirable than overprediction. Contrary to expectations, treating the data as a single region - rather than splitting the data into above- and below-yield stress regions - provided the lowest mean squared errors for Inconel 617. The use of heat- and processing-specific tensile strength values greatly improved the goodness of fit of the Wilshire equation to the Nimonic 105 data and reduced the error in all cases. For Inconel 617, the use of data with rupture times less than 10,000 $\mathrm{h}$ to extrapolate creep life gave roughly similar goodness of fit and error compared to using all data. Surprisingly, for Nimonic 105 the use of data with rupture times less than $10,000 \mathrm{~h}$ to extrapolate creep life resulted in a significant reduction in goodness of fit and error compared to using all data, e.g., $R^{2}$ of 0.880 versus 0.950 when $Q_{C}^{*}$ was determined using the correlation optimization method. Considering that the longest Nimonic 105 experimental data point was 34,995 h time to rupture, this result would suggest that further investigation should be made of the ability of the Wilshire equation to accurately predict long-term creep strength from short-term creep rupture strength data.

In its basic form, the Wilshire equation is a simple method to quickly estimate long-term creep life using only three fitting constants-yet if an extensive analysis with a high level of precision is required, its complexity can be increased to improve the statistical fit of the Wilshire equation to available data. Evans [41,49-54] has proposed more sophisticated methods of fitting the Wilshire equation to complex data sets, including the handling of data collected from specimens of multiple batches [41], determining $Q_{C}^{*}$ as a function of temperature [41], statistically determining the number of stress regions [49], and utilizing additional batch characteristics [50]. The Wilshire equation is modular in that many combinations of these methods can be used, which gives it flexibility for a wide variety of applications. If only a preliminary estimate of long-term creep strength (e.g., at 100,000 h or longer design life) is needed, such as in the early stages of new alloy development, use of the Wilshire equation in its original form with $Q_{C}^{*}$ equal to the activation energy of self-diffusion would probably be sufficient. More complex analyses (which, in essence, increase the number of fitting constants) would be needed if the intent is to use the Wilshire equation for component design or for establishing long-term creep strength values for design codes, instead of the equations now used in various design codes, and which contain more than three fitting constants. 
Author Contributions: Conceptualization, V.C.III; Methodology, V.C.III, C.G. and M.R.; Validation, C.G. and M.R.; Formal Analysis, C.G. and M.R.; Investigation, V.C.III, C.G., and M.R.; Resources, V.C.III; Data Curation, V.C.III, C.G., and M.R.; Writing-Original Draft Preparation, C.G. and M.R; Writing-Review \& Editing, V.C.III; Visualization, C.G. and M.R.; Supervision, V.C. III; Project Administration, V.C. III; Funding Acquisition, V.C.III.Funding: KeyLogic Systems, Inc.'s contributions to this work were funded by the National Energy Technology Laboratory under the Mission Execution and Strategic Analysis contract (DE-FE0025912) for support services.

Acknowledgments: This research was made possible thanks to the Mickey Leland Fellowship Program, a United States Department of Energy funded program.

Conflicts of Interest: The authors declare no conflict of interest.

Disclaimer: This report was prepared as an account of work sponsored by an agency of the United States Government. Neither the United States Government nor any agency thereof, nor any of their employees, makes any warranty, express or implied, or assumes any legal liability or responsibility for the accuracy, completeness, or usefulness of any information, apparatus, product, or process disclosed, or represents that its use would not infringe privately owned rights. Reference therein to any specific commercial product, process, or service by trade name, trademark, manufacturer, or otherwise does not necessarily constitute or imply its endorsement, recommendation, or favoring by the United States Government or any agency thereof. The views and opinions of authors expressed therein do not necessarily state or reflect those of the United States Government or any agency thereof.

\section{Appendix A}

All Data
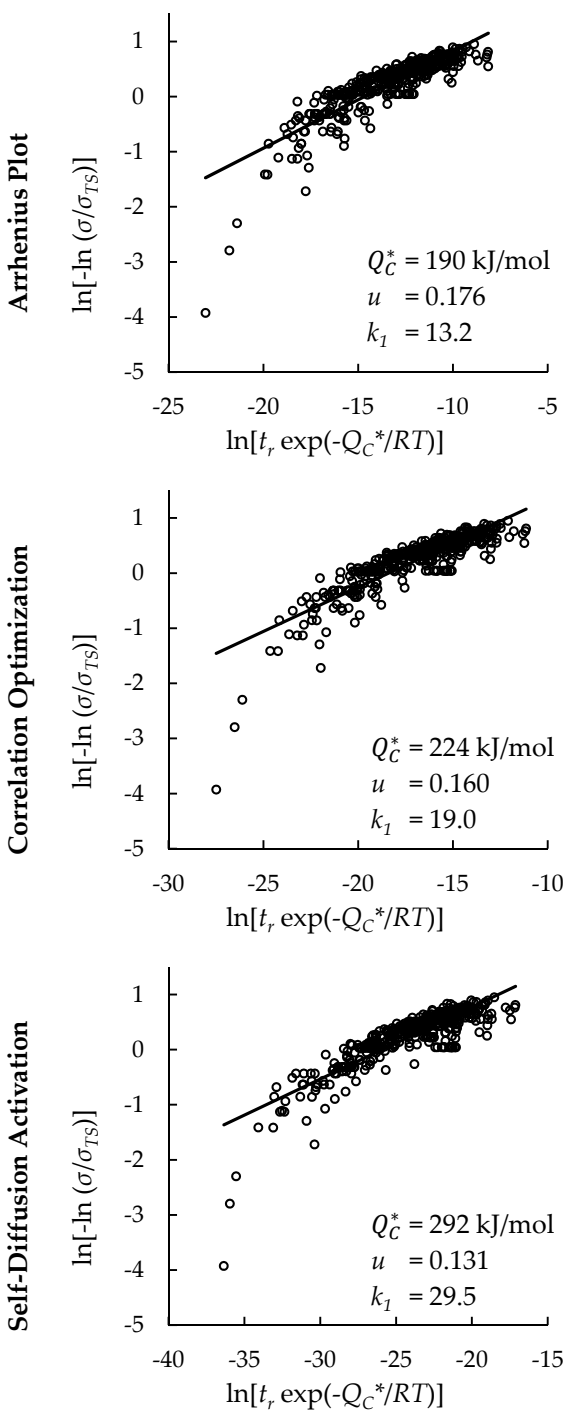

Data with $t_{r}<10,000 \mathrm{~h}$
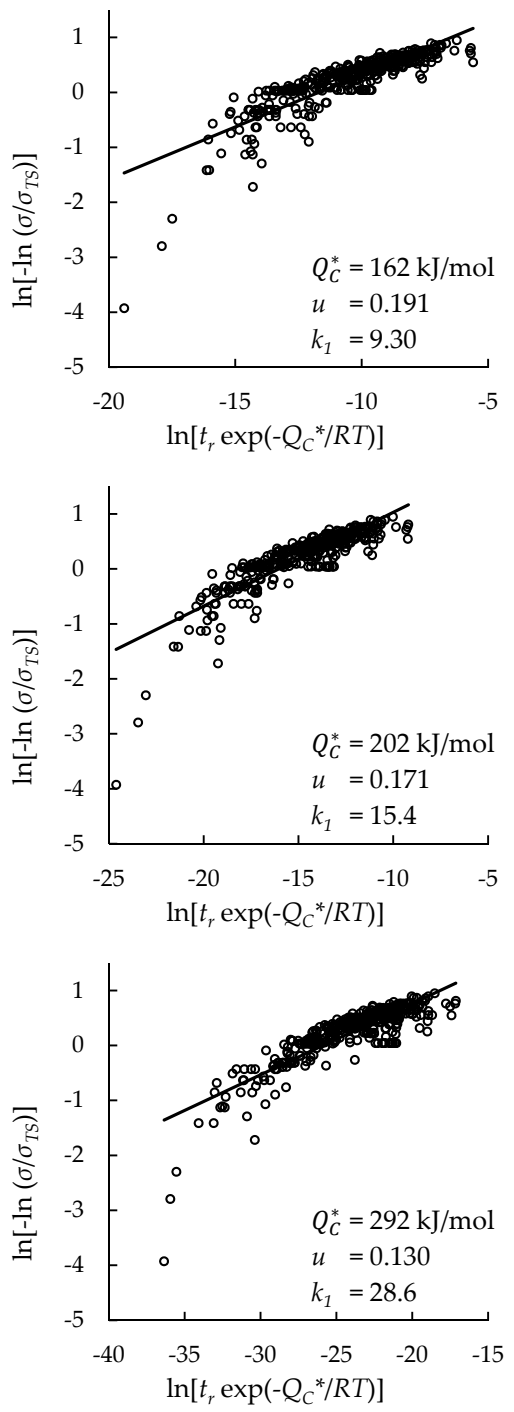

Figure A1. Wilshire plots of Inconel 617 creep rupture data treated as a single region. 

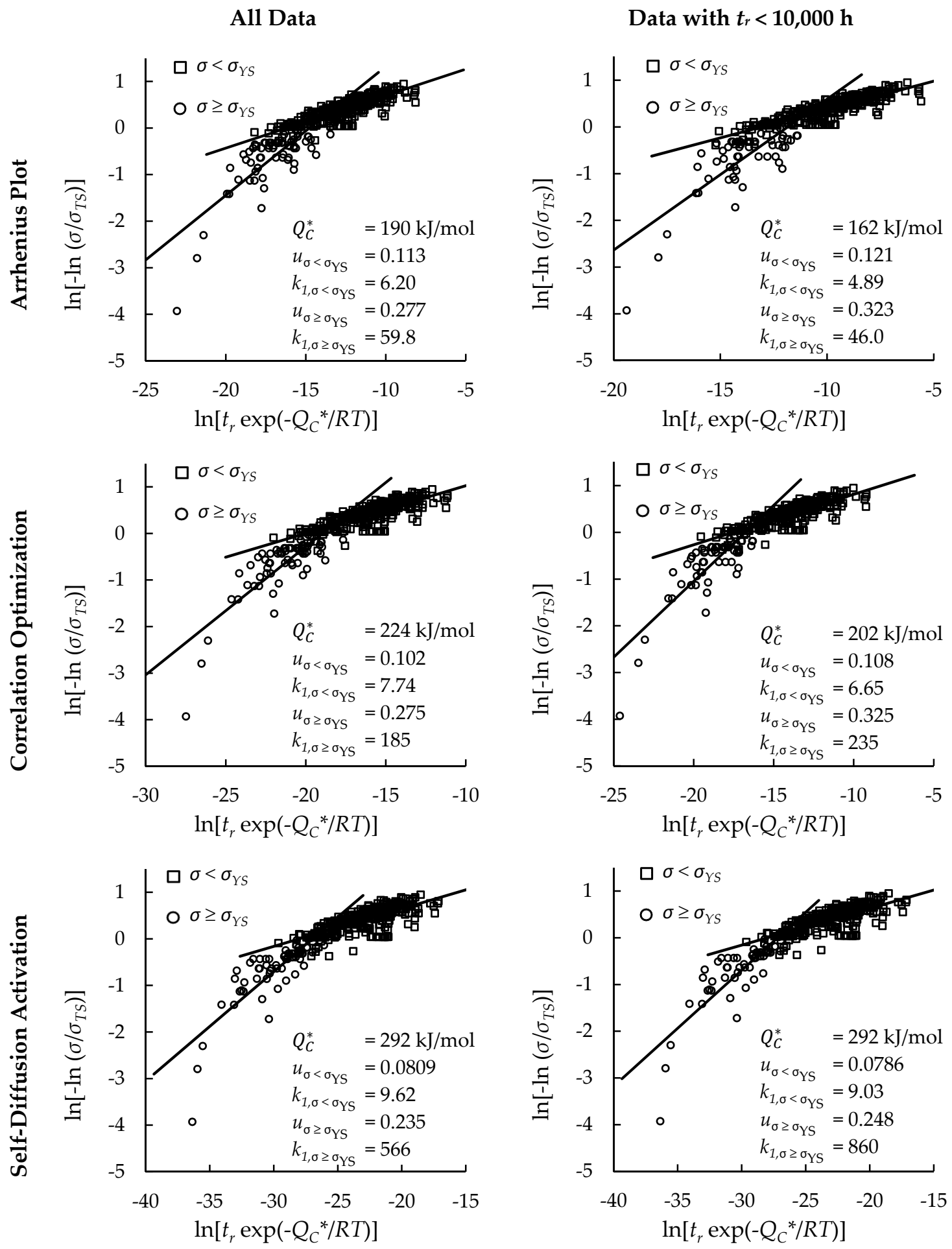

Figure A2. Wilshire plots of Inconel 617 creep rupture data split into above- and below-yield stress regions. 

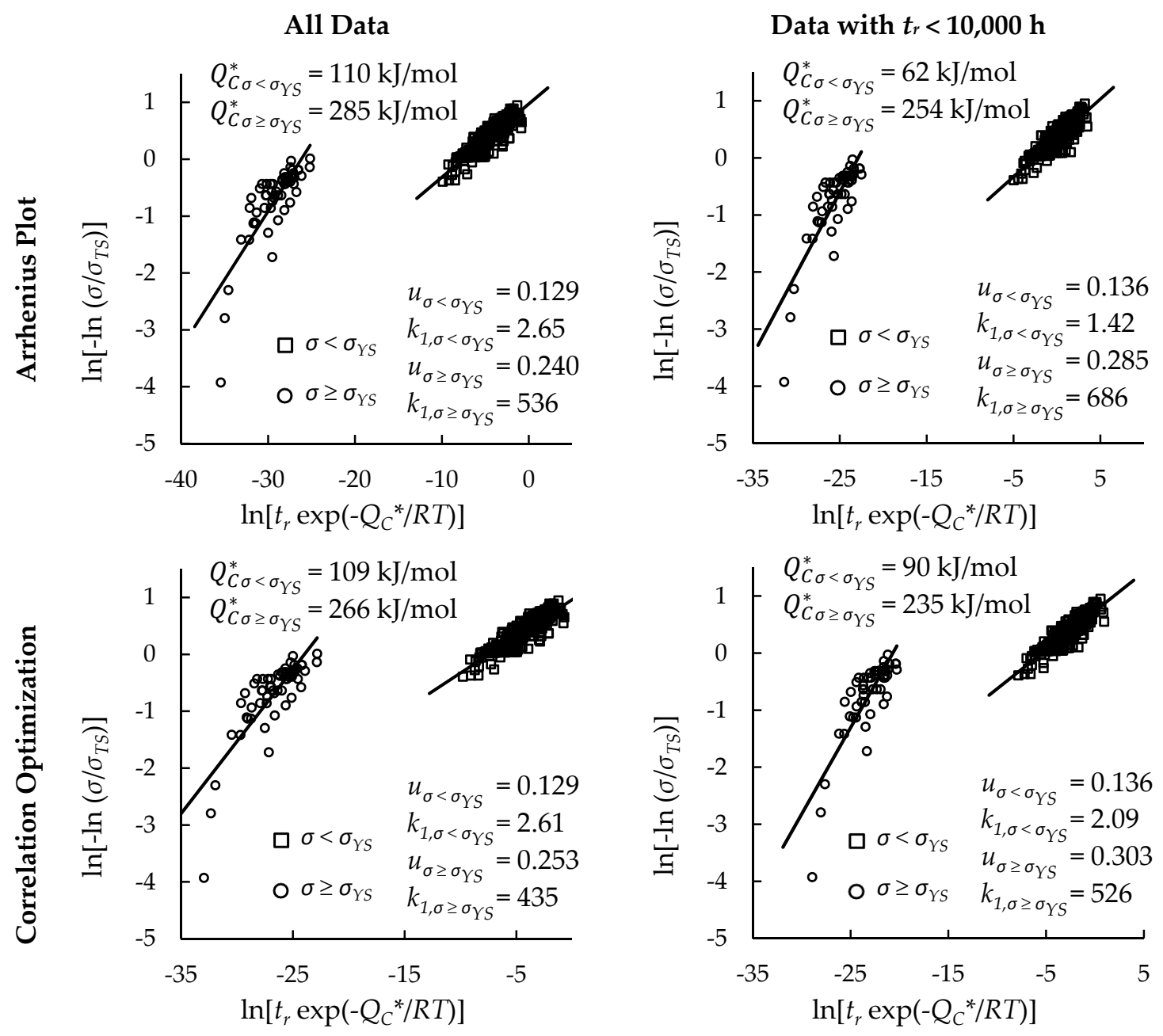

Figure A3. Wilshire plots of Inconel 617 creep rupture data split into above- and below-yield stress regions. 

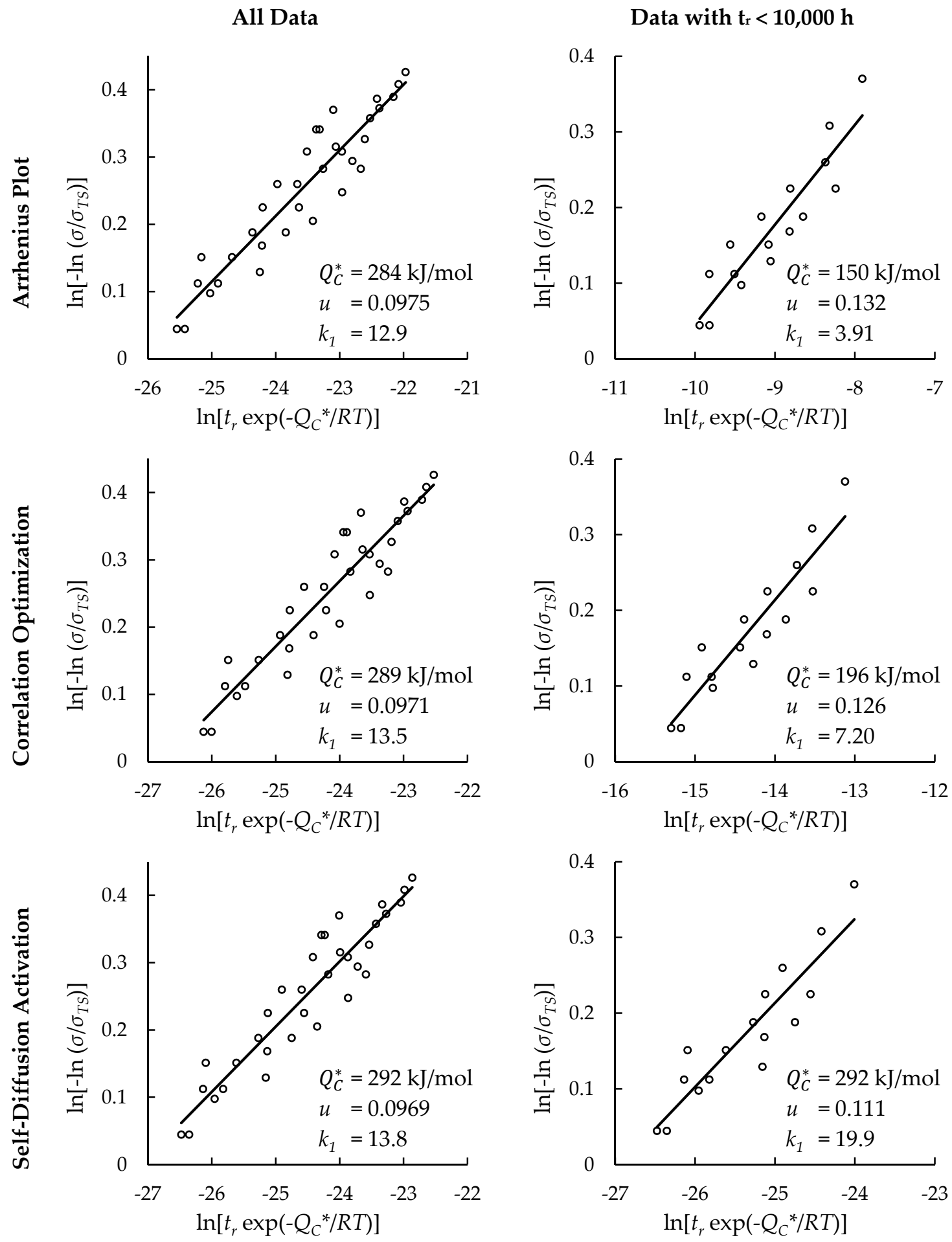

Figure A4. Wilshire plots of Nimonic 105 creep rupture data using average tensile strength values. 

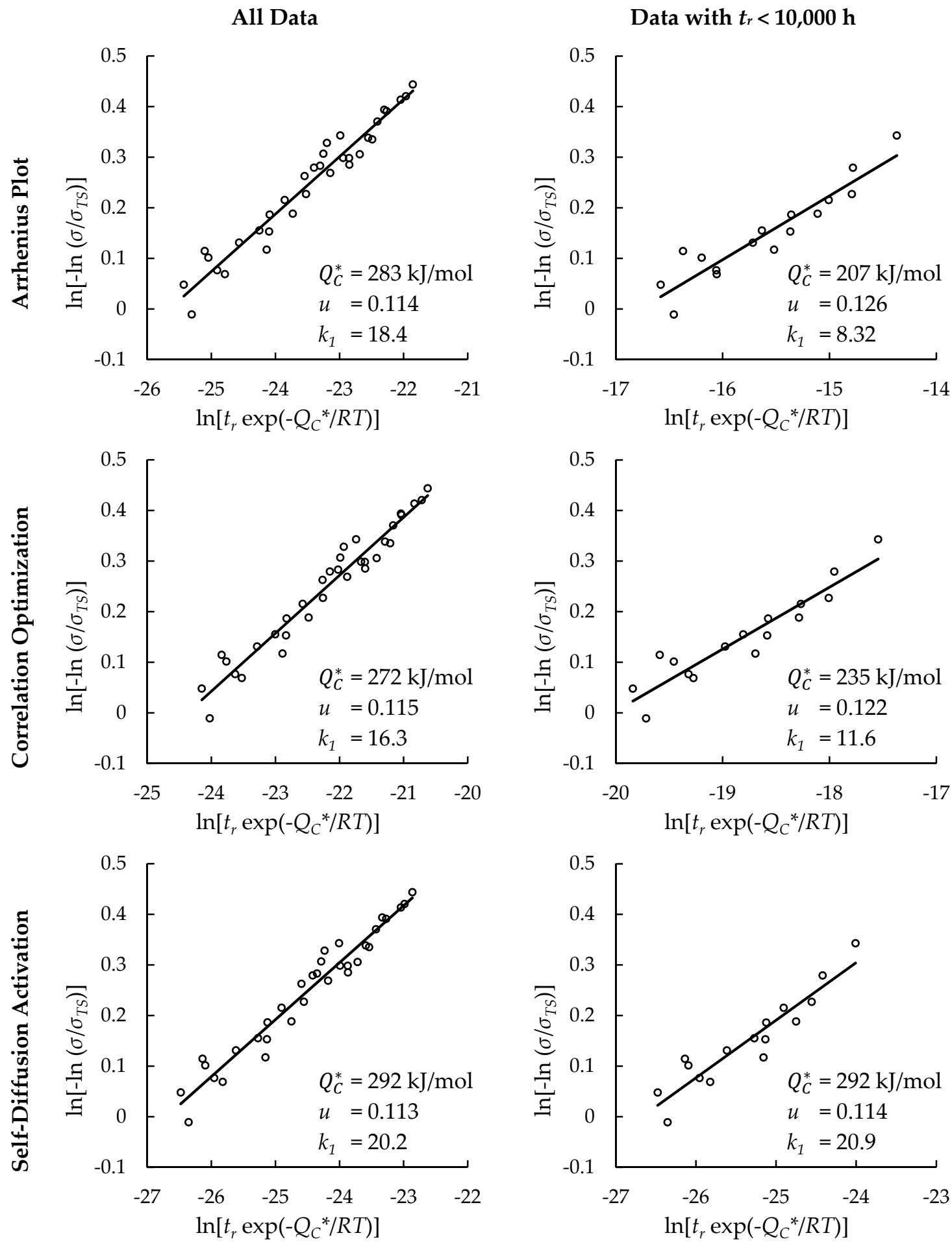

Figure A5. Wilshire plots of Nimonic 105 creep rupture data using heat- and processing-specific tensile strength values. 


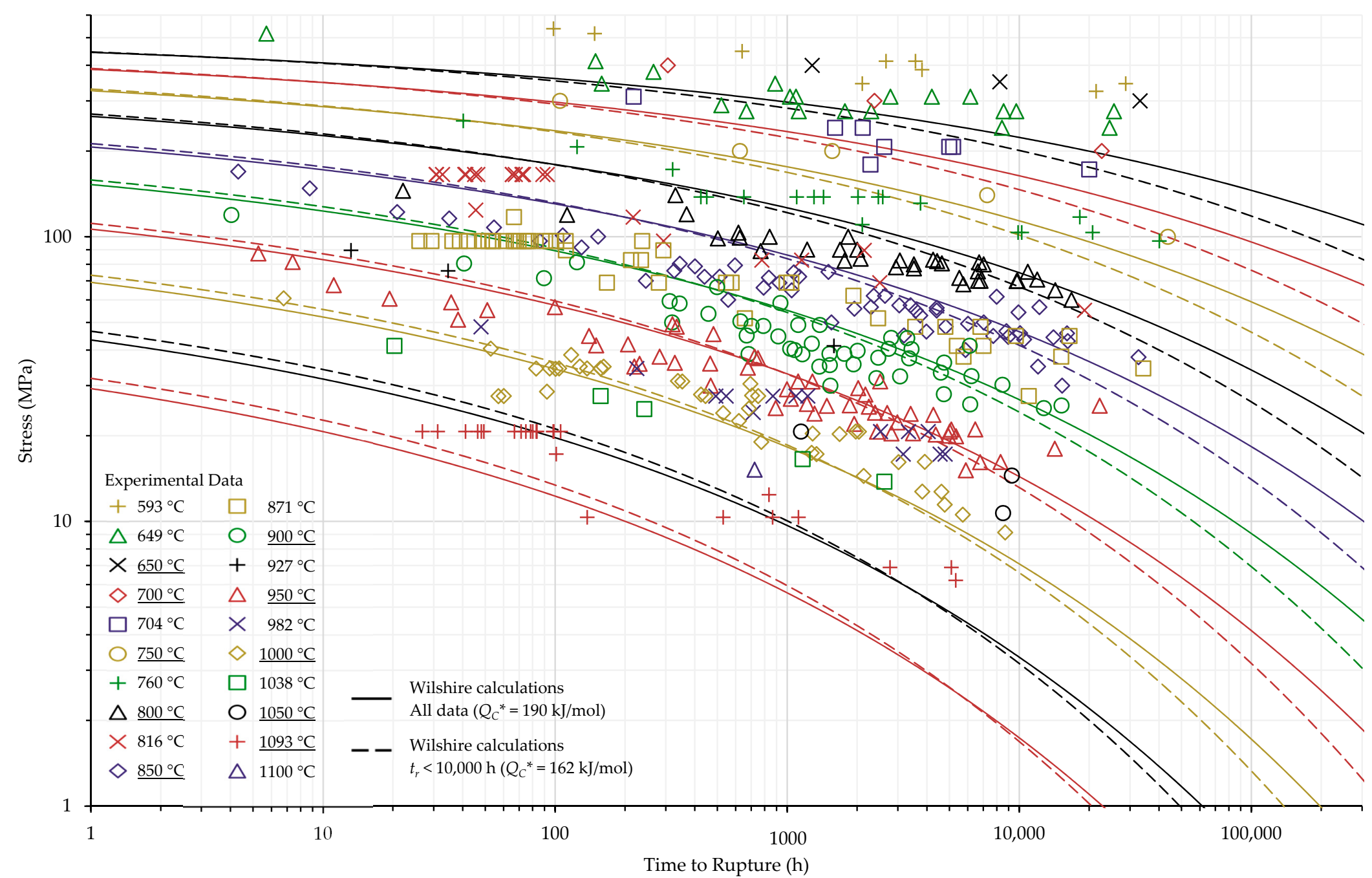

Figure A6. Single region calculations of the Wilshire equation with $Q_{C}^{*}$ determined using Arrhenius plots for Inconel 617 shown at underlined temperatures. 


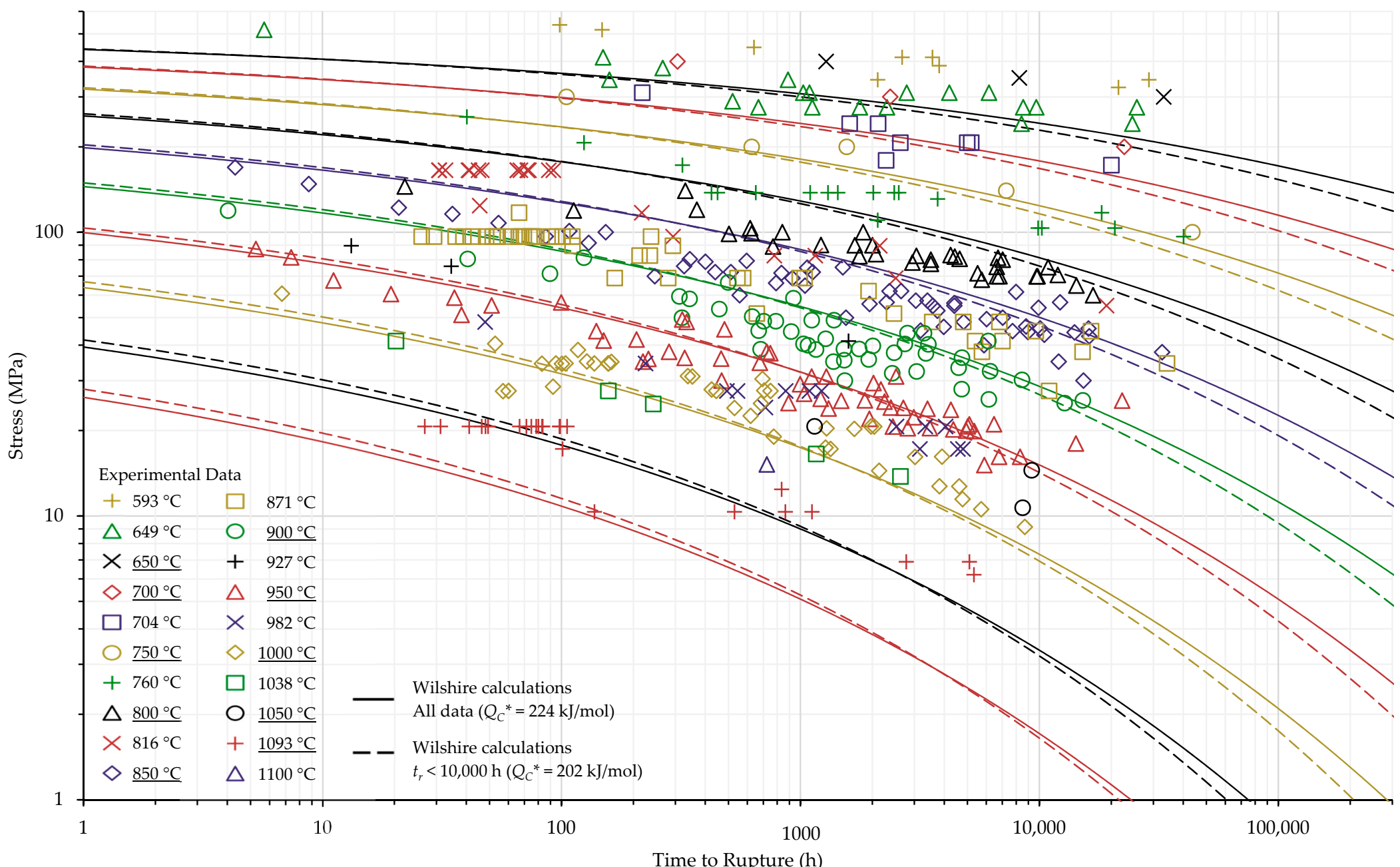

Figure A7. Single region calculations of the Wilshire equation with $Q_{C}^{*}$ determined by optimizing the correlation of data on a Wilshire plot for Inconel 617 shown at underlined temperatures. 


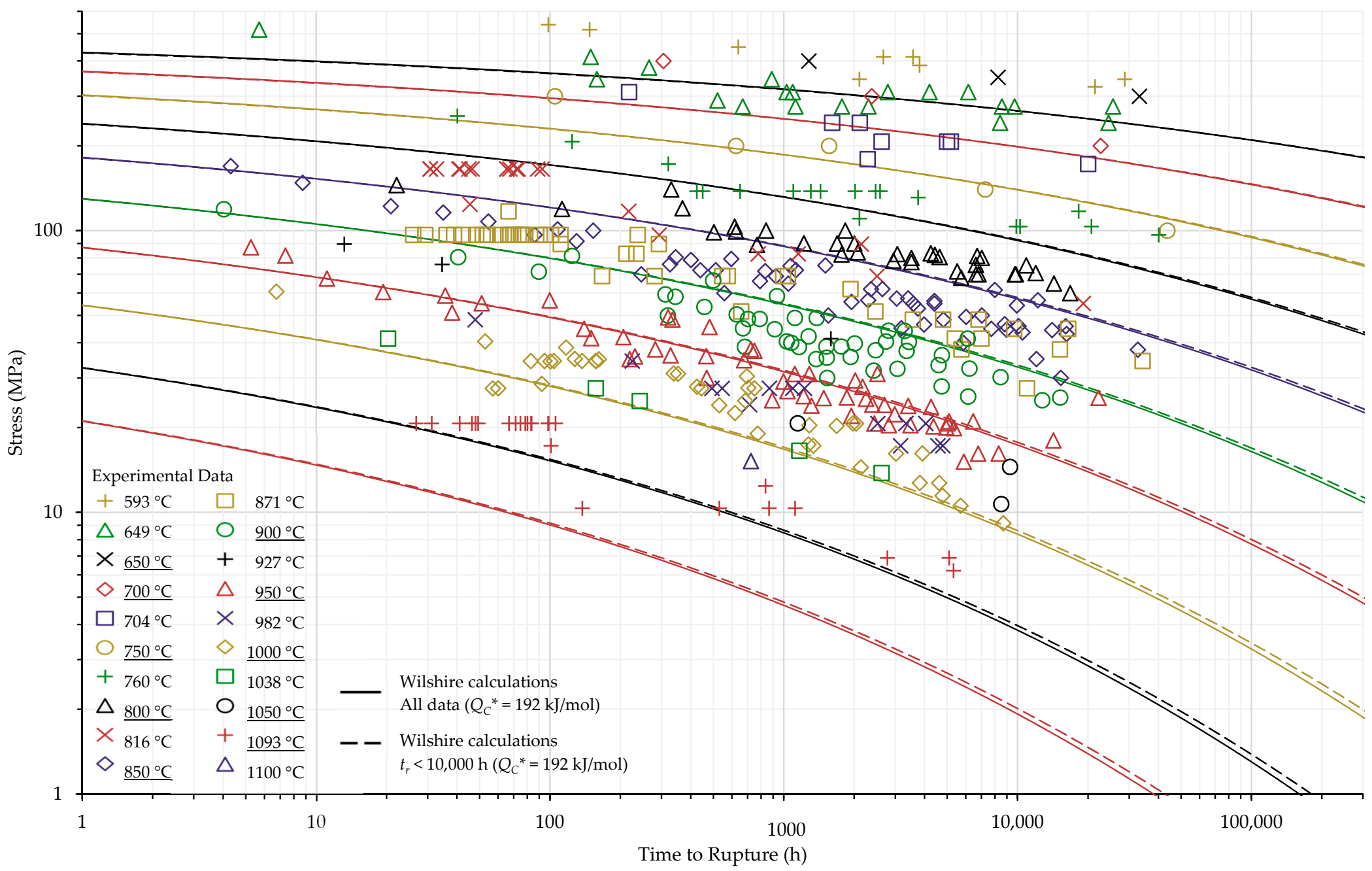

Figure A8. Single region calculations of the Wilshire equation with the self-diffusion activation energy of nickel in a nickel lattice as $Q_{C}^{*}$ for Inconel 617 shown at underlined temperatures. 


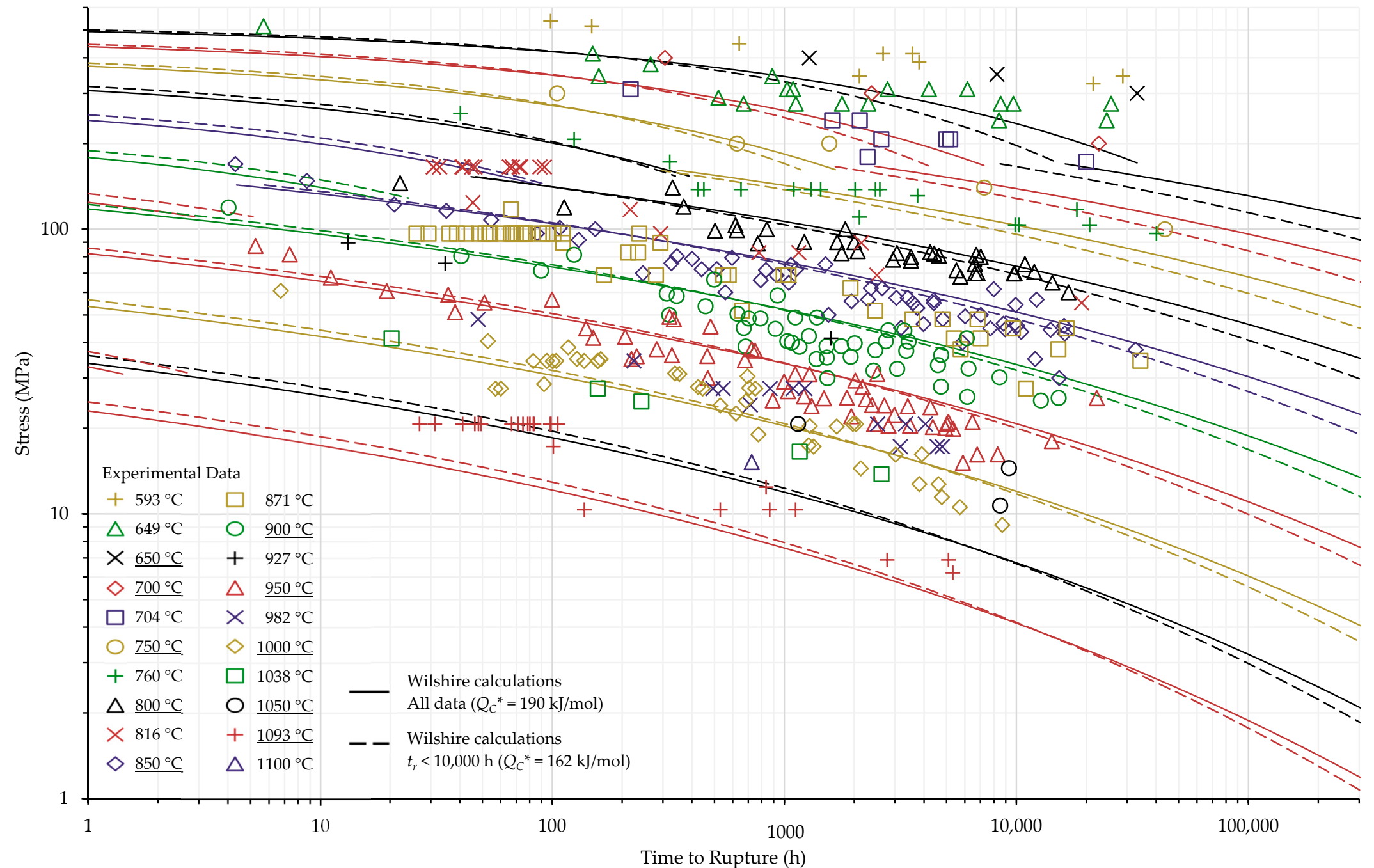

Figure A9. Split region calculations of the Wilshire equation with $Q_{C}^{*}$ determined using Arrhenius plots for Inconel 617 shown at underlined temperatures. 


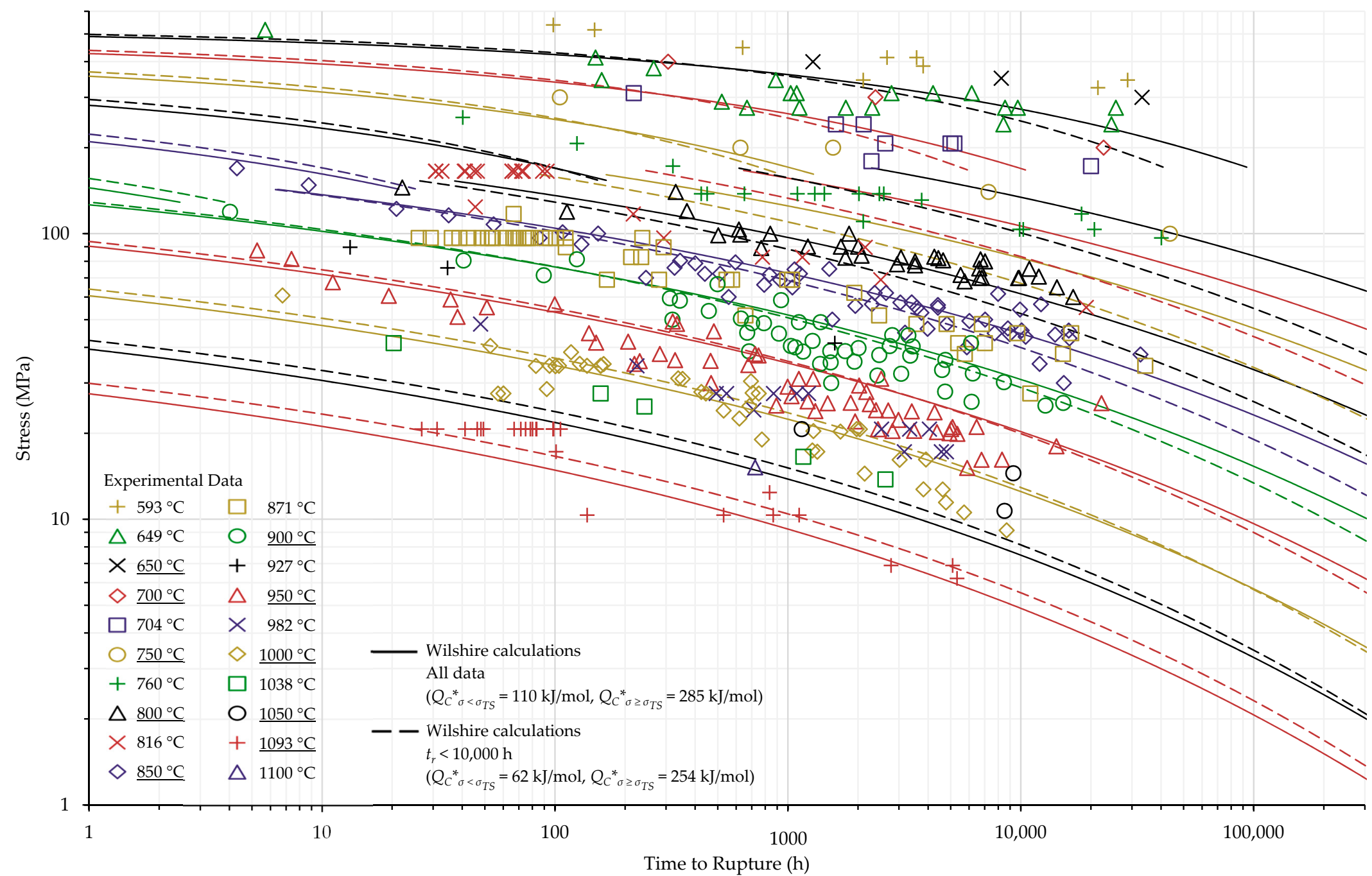

Figure A10. Split region calculations of the Wilshire equation with $Q_{C}^{*}$ determined using Arrhenius plots for Inconel 617 shown at underlined temperatures. 


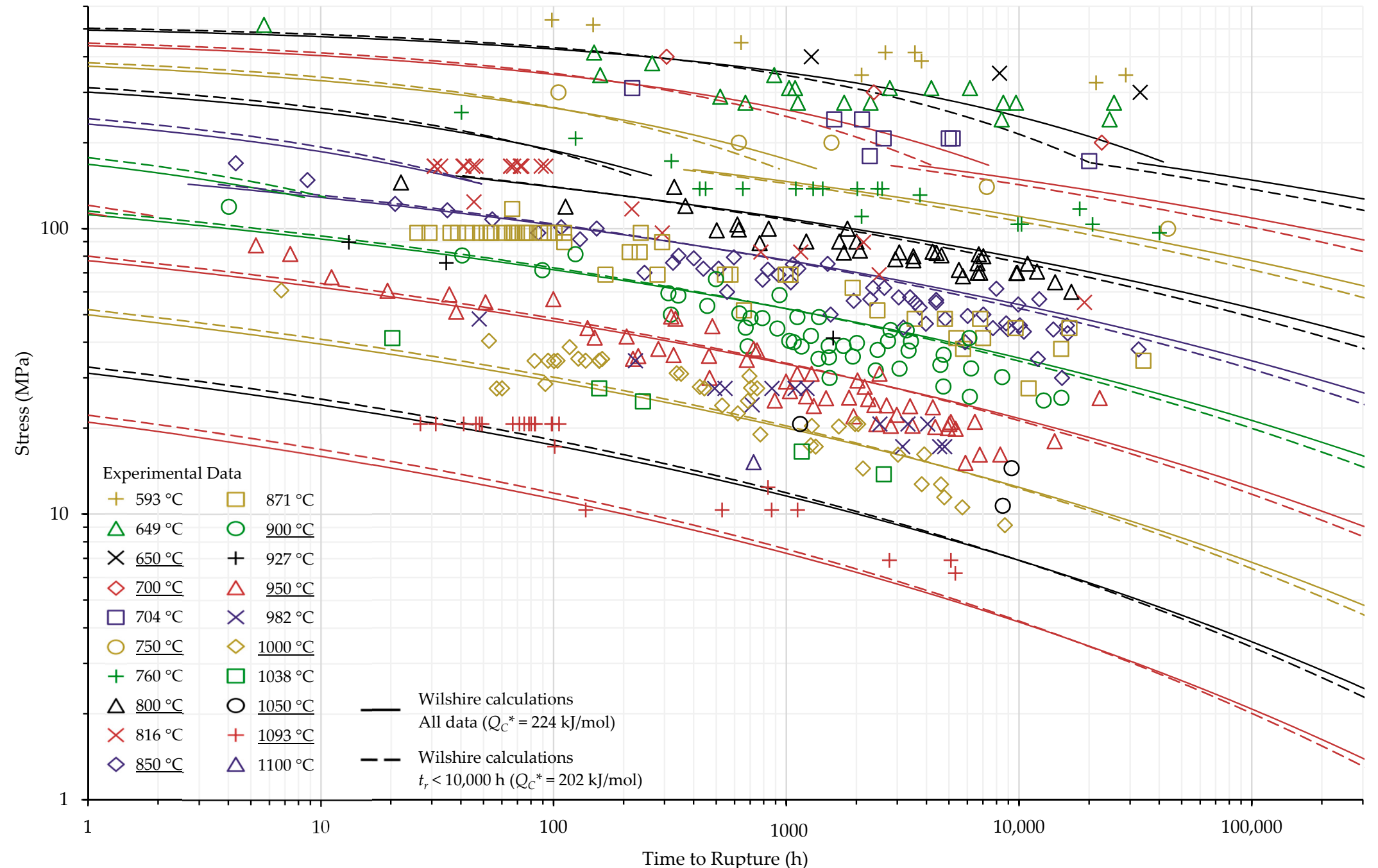

Figure A11. Split region calculations of the Wilshire equation with $Q_{C}^{*}$ determined by optimizing the correlation of data on a Wilshire plot for Inconel 617 shown at underlined temperatures. 


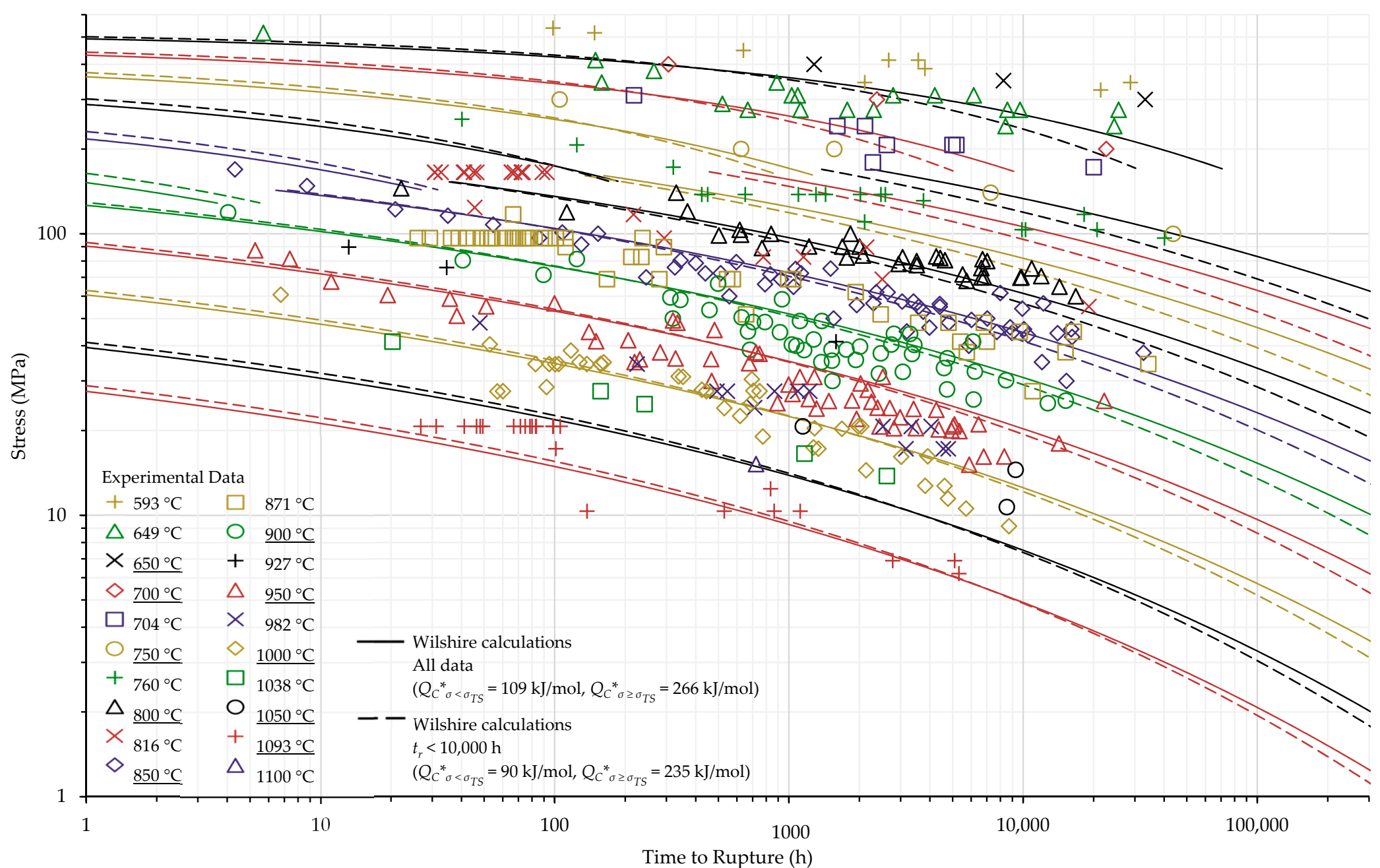

Figure A12. Split region calculations of the Wilshire equation with $Q_{C}^{*}$ determined by optimizing the correlation of data on a Wilshire plot for Inconel 617 shown at underlined temperatures. 


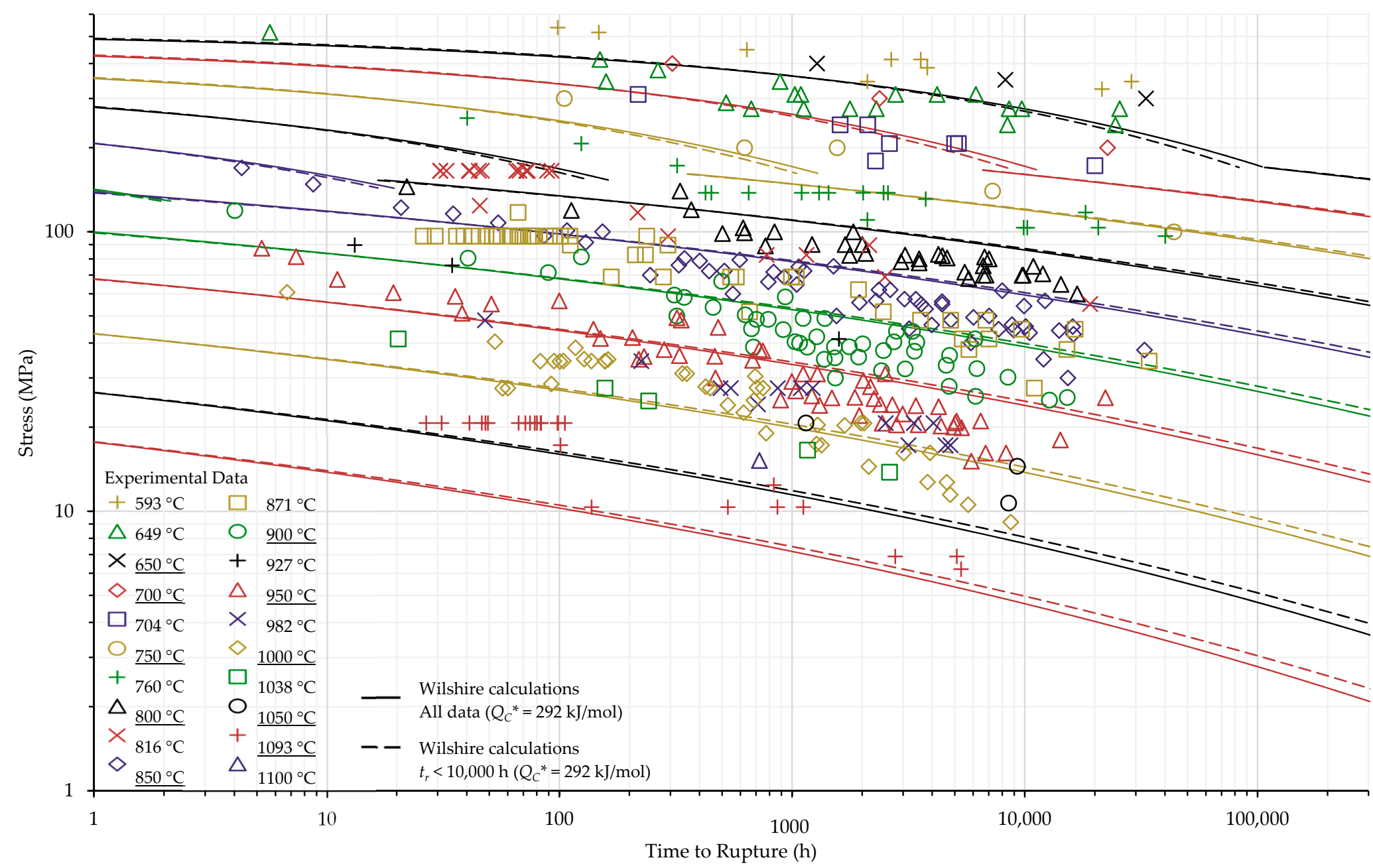

Figure A13. Single region calculations of the Wilshire equation with the self-diffusion activation energy of nickel in a nickel lattice as $Q_{C}^{*}$ for Inconel 617 shown at underlined temperatures. 


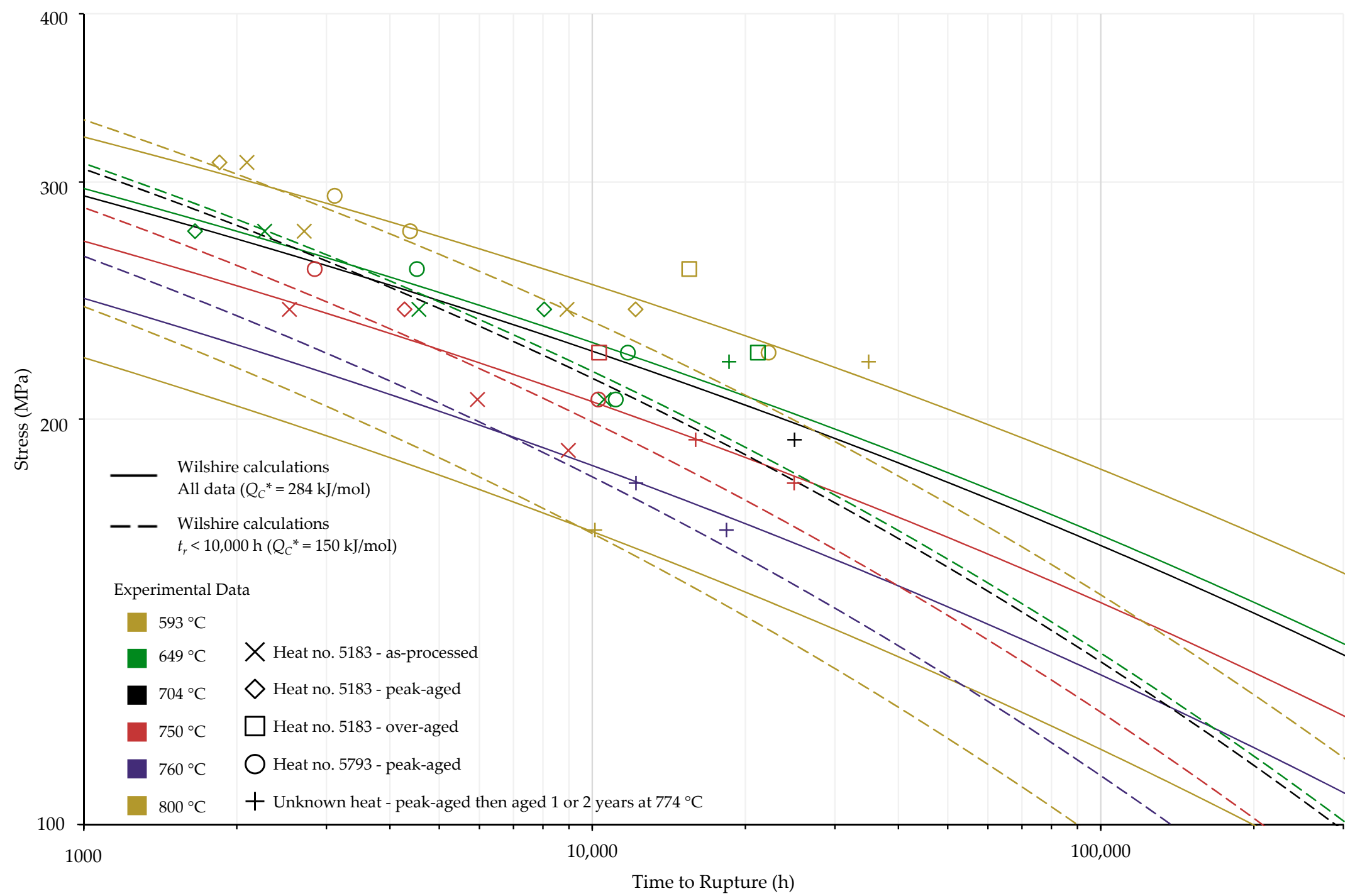

Figure A14. Calculations of the Wilshire equation for Nimonic 105 using average tensile strength values with $Q_{C}^{*}$ determined using Arrhenius plots. 


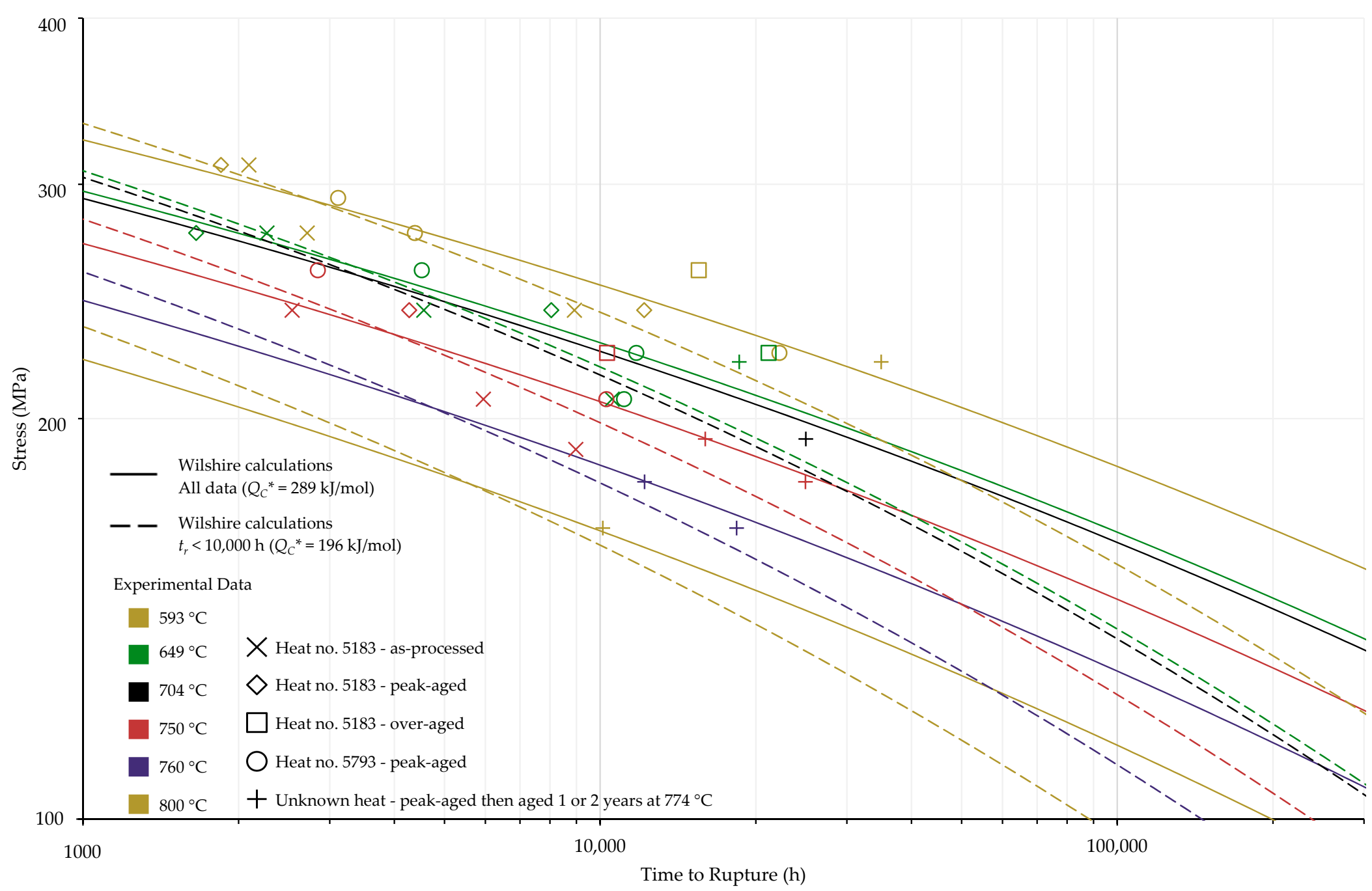

Figure A15. Calculations of the Wilshire equation for Nimonic 105 using average tensile strength values with $Q_{C}^{*}$ determined by optimizing the correlation of data on a Wilshire plot. 


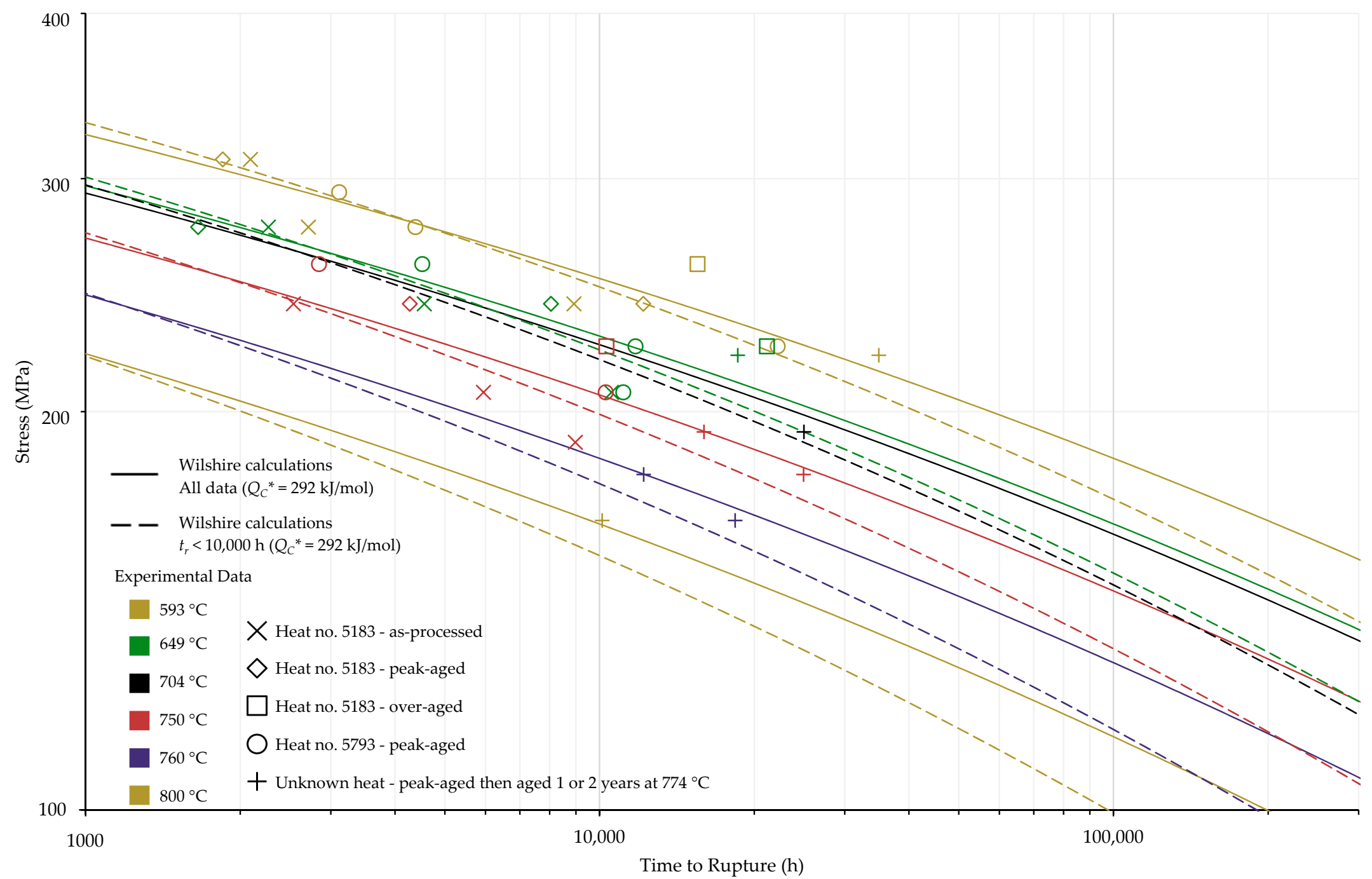

Figure A16. Calculations of the Wilshire equation for Nimonic 105 using average tensile strength values with the self-diffusion activation energy of nickel in a nickel lattice as $Q_{C}^{*}$. 


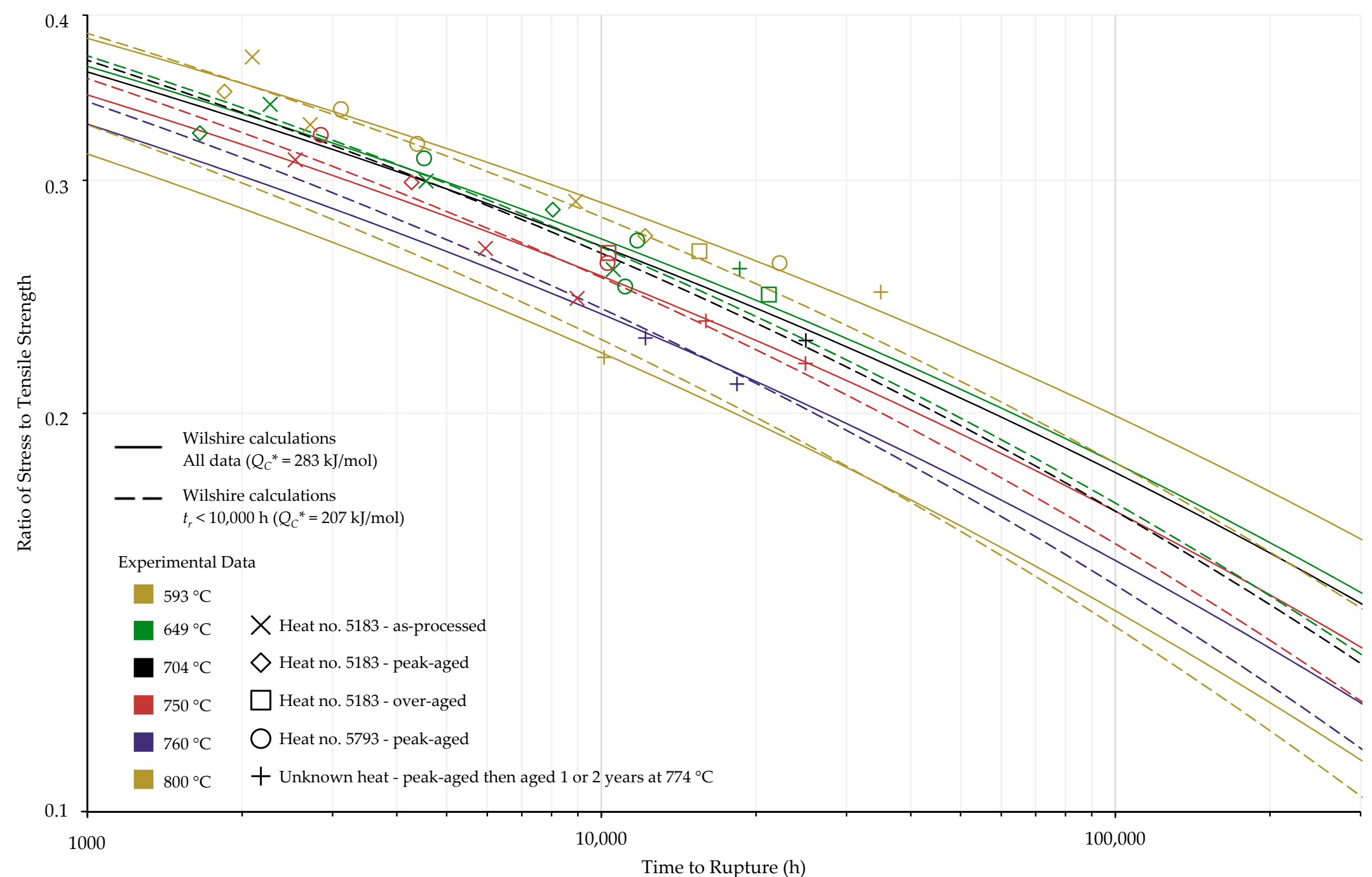

Figure A17. Split region calculations of the Wilshire equation for Nimonic 105 using heat- and processing-specific tensile strength values with $Q_{C}^{*}$ determined using Arrhenius plots. 


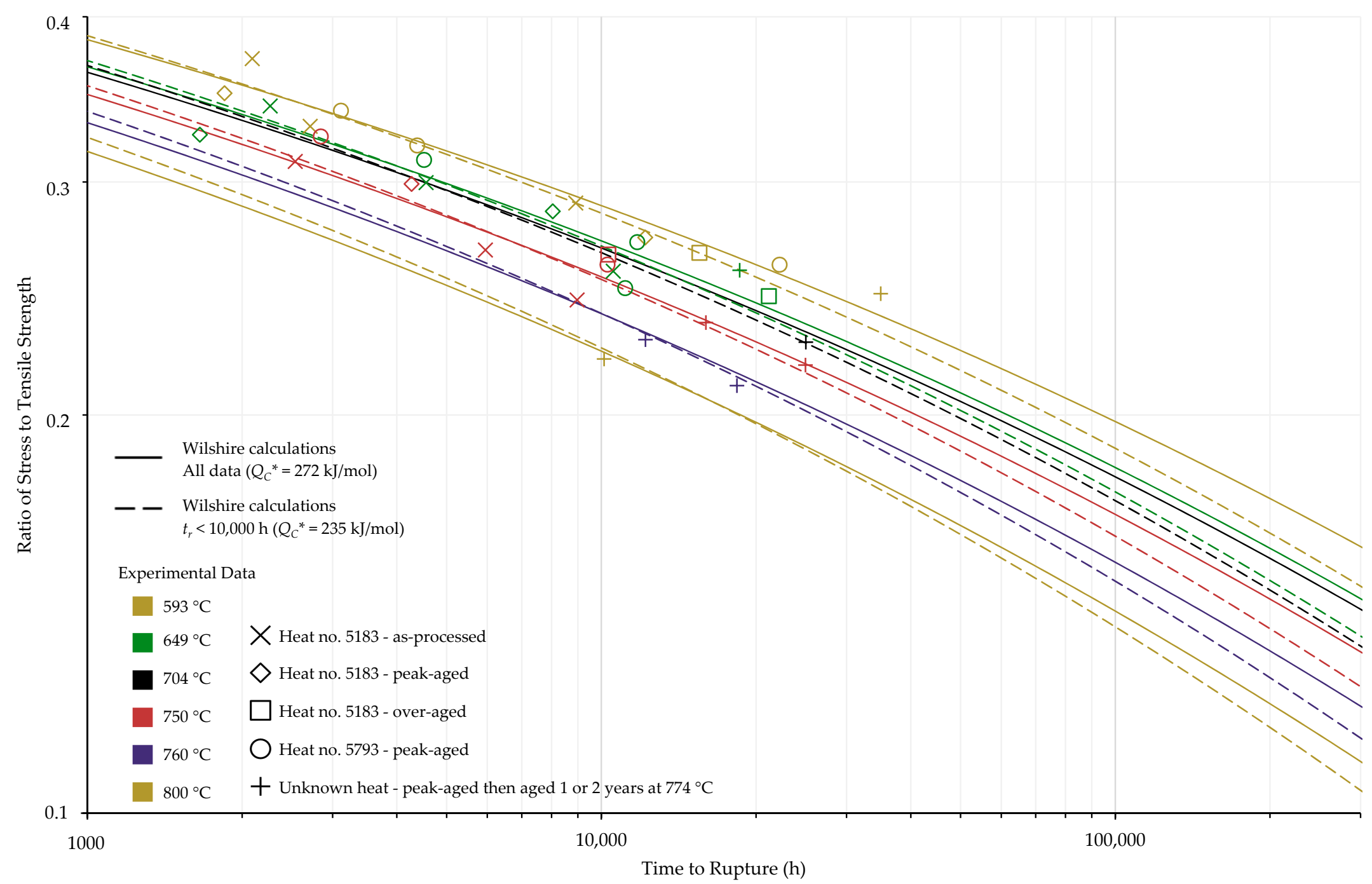

Figure A18. Calculations of the Wilshire equation for Nimonic 105 using heat- and processing-specific tensile strength values with $Q_{C}^{*}$ determined by optimizing the correlation of data on a Wilshire plot. 


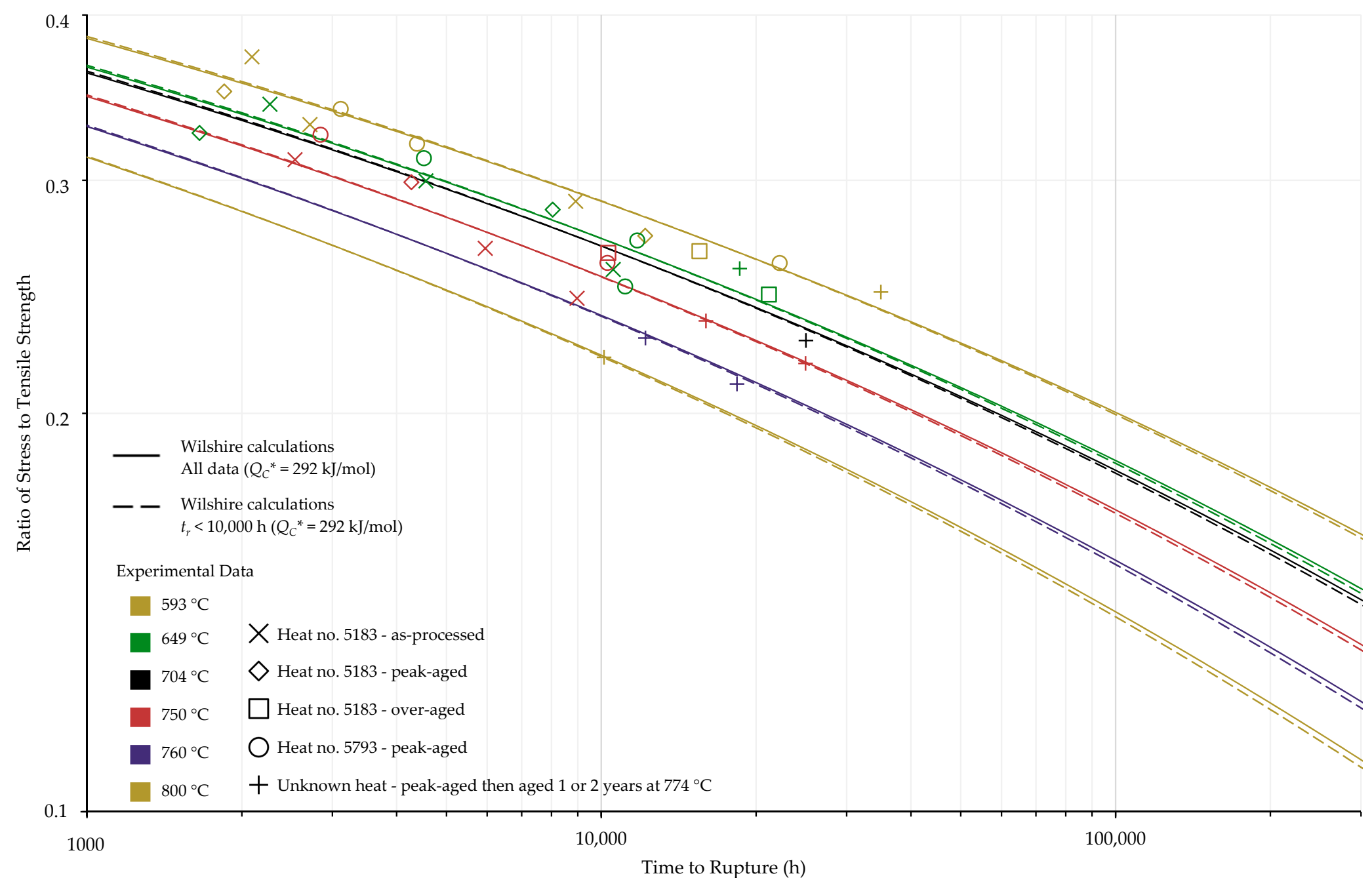

Figure A19. Calculations of the Wilshire equation for Nimonic 105 using heat- and processing-specific tensile strength values with the self-diffusion activation energy of nickel in a nickel lattice as $Q_{C}^{*}$. 
Table A1. Nimonic 105 tensile strength values [3,4,21].

\begin{tabular}{|c|c|c|c|c|}
\hline Temperature & Heat No. & Processing Condition & Tensile Strength (MPa) & Yield Strength (MPa) \\
\hline \multirow{5}{*}{$760^{\circ} \mathrm{C}$} & \multirow{3}{*}{5183} & $\mathrm{AP}$ & 834 & 737 \\
\hline & & PA & 886 & 724 \\
\hline & & OA & 975 & 722 \\
\hline & 5793 & $\mathrm{PA}$ & 863 & 719 \\
\hline & Unknown & $\mathrm{PA}^{1}$ & 893 & 687 \\
\hline \multirow{5}{*}{$816^{\circ} \mathrm{C}$} & \multirow{3}{*}{5183} & $\mathrm{AP}$ & 718 & 680 \\
\hline & & PA & 728 & 625 \\
\hline & & OA & 720 & 605 \\
\hline & 5793 & PA & 729 & 672 \\
\hline & Unknown & $\mathrm{PA}^{1}$ & 751 & 610 \\
\hline
\end{tabular}

${ }^{1}$ Aged for $1-2$ years at $774^{\circ} \mathrm{C}$. 
Table A2. Calculated times to rupture (h) for each method to determine $Q_{C}^{*}$ for Nimonic 105.

\begin{tabular}{|c|c|c|c|c|c|c|c|c|c|c|c|c|c|c|c|c|c|c|}
\hline \multirow{2}{*}{$\begin{array}{l}\text { Heat No. } \\
{[3,4,21]}\end{array}$} & \multirow{2}{*}{$\begin{array}{c}\text { Processing } \\
\text { Condition } \\
{[3,4,21]}\end{array}$} & \multirow{2}{*}{$\begin{array}{c}\text { Temperature } \\
\left({ }^{\circ} \mathrm{C}\right) \\
{[3,4,21]}\end{array}$} & \multirow{2}{*}{$\begin{array}{c}\text { Applied } \\
\text { Stress (MPa) } \\
{[3,4,21]}\end{array}$} & \multirow{2}{*}{$\begin{array}{c}\text { Heat- and } \\
\text { Processing-Specific } \\
\text { TS (MPa) }[3,4,21]\end{array}$} & \multirow{2}{*}{$\begin{array}{c}\text { Experimental Time } \\
\text { to Rupture (h) } \\
{[3,4,21]}\end{array}$} & \multicolumn{13}{|c|}{ Calculated Time to Rupture (h) } \\
\hline & & & & & & $\begin{array}{c}\text { Case } \\
1\end{array}$ & $\begin{array}{c}\text { Case } \\
2\end{array}$ & $\begin{array}{c}\text { Case } \\
3 \\
\end{array}$ & $\begin{array}{c}\text { Case } \\
4\end{array}$ & $\begin{array}{c}\text { Case } \\
5\end{array}$ & $\begin{array}{c}\text { Case } \\
6\end{array}$ & $\begin{array}{c}\text { Case } \\
7\end{array}$ & $\begin{array}{c}\text { Case } \\
8\end{array}$ & $\begin{array}{c}\text { Case } \\
9\end{array}$ & $\begin{array}{c}\text { Case } \\
10 \\
\end{array}$ & $\begin{array}{c}\text { Case } \\
11 \\
\end{array}$ & $\begin{array}{c}\text { Case } \\
12 \\
\end{array}$ & $\begin{array}{l}\text { LMP } \\
\text { Equation }\end{array}$ \\
\hline 5183 & AP & 760 & 310 & 834 & 2092 & 1545 & 1545 & 1545 & 1771 & 1773 & 1768 & 1281 & 1324 & 1340 & 1401 & 1400 & 1378 & 1729 \\
\hline 5183 & АР & 760 & 276 & 834 & 2713 & 4617 & 4638 & 4651 & 4572 & 4514 & 4620 & 3170 & 3350 & 3637 & 5054 & 5263 & 5717 & 4950 \\
\hline 5183 & AP & 760 & 241 & 834 & 8914 & 14,068 & 14,201 & 14,281 & 12,011 & 11,688 & 12,284 & 7934 & 8571 & 9998 & 11,949 & 12,795 & 14,843 & 13,395 \\
\hline 5183 & $\mathrm{AP}$ & 774 & 276 & 805 & 2268 & 1999 & 1989 & 1984 & 2091 & 2110 & 2075 & 1933 & 1891 & 1734 & 2699 & 2665 & 2589 & 2640 \\
\hline 5183 & AP & 774 & 241 & 805 & 4560 & 6351 & 6352 & 6352 & 5695 & 5663 & 5722 & 4979 & 4982 & 4920 & 6590 & 6697 & 6966 & 7052 \\
\hline 5183 & АР & 774 & 207 & 805 & 10,546 & 20,879 & 20,988 & 21,055 & 15,976 & 15,643 & 16,261 & 13,132 & 13,448 & 14,326 & 16,520 & 17,296 & 19,301 & 18,524 \\
\hline 5183 & AP & 788 & 241 & 776 & 2537 & 2834 & 2809 & 2793 & 2677 & 2720 & 2643 & 3094 & 2871 & 2407 & 3600 & 3475 & 3244 & 3775 \\
\hline 5183 & $\mathrm{AP}$ & 788 & 207 & 776 & 5946 & 9720 & 9683 & 9662 & 7791 & 7790 & 7795 & 8398 & 7982 & 7234 & 9324 & 9281 & 9319 & 9792 \\
\hline 5183 & AP & 788 & 190 & 776 & 8969 & 18,348 & 18,329 & 18,319 & 13,513 & 13,401 & 13,614 & 14,032 & 13,503 & 12,739 & 15,230 & 15,403 & 16,056 & 16,106 \\
\hline 5183 & $\mathrm{OA}$ & 760 & 259 & 975 & 15,515 & 8032 & 8088 & 8122 & 7388 & 7242 & 7511 & 13,681 & 14,974 & 18,228 & 7751 & 8184 & 9185 & 8187 \\
\hline 5183 & $\mathrm{OA}$ & 774 & 224 & 911 & 21,173 & 11,450 & 11,481 & 11,499 & 9492 & 9366 & 9598 & 16,940 & 17,454 & 18,968 & 10,388 & 10,714 & 11,539 & 11,405 \\
\hline 5183 & $\mathrm{OA}$ & 788 & 224 & 847 & 10,317 & 5221 & 5188 & 5168 & 4546 & 4582 & 4518 & 8812 & 8386 & 7628 & 5770 & 5655 & 5473 & 6067 \\
\hline 5183 & PA & 760 & 310 & 886 & 1849 & 1545 & 1545 & 1545 & 1771 & 1773 & 1768 & 2060 & 2155 & 2262 & 2170 & 2199 & 2239 & 1729 \\
\hline 5183 & PA & 760 & 241 & 886 & 12,170 & 14,068 & 14,201 & 14,281 & 12,011 & 11,688 & 12,284 & 11,618 & 12,665 & 15,222 & 11,949 & 12,795 & 14,843 & 13,395 \\
\hline 5183 & PA & 774 & 276 & 847 & 1655 & 1999 & 1989 & 1984 & 2091 & 2110 & 2075 & 2793 & 2757 & 2602 & 2699 & 2665 & 2589 & 2640 \\
\hline 5183 & PA & 774 & 241 & 847 & 8045 & 6351 & 6352 & 6352 & 5695 & 5663 & 5722 & 6913 & 6972 & 7064 & 6590 & 6697 & 6966 & 7052 \\
\hline 5183 & PA & 788 & 241 & 807 & 4274 & 2834 & 2809 & 2793 & 2677 & 2720 & 2643 & 4036 & 3770 & 3226 & 3600 & 3475 & 3244 & 3775 \\
\hline 5793 & PA & 760 & 293 & 863 & 3114 & 2667 & 2673 & 2676 & 2842 & 2825 & 2854 & 2592 & 2726 & 2914 & 3308 & 3398 & 3574 & 2949 \\
\hline 5793 & PA & 760 & 276 & 863 & 4382 & 4617 & 4638 & 4651 & 4572 & 4514 & 4620 & 4025 & 4278 & 4733 & 5054 & 5263 & 5717 & 4950 \\
\hline 5793 & PA & 760 & 224 & 863 & 22,216 & 24,872 & 25,168 & 25,348 & 19,682 & 19,012 & 20,255 & 15,491 & 17,004 & 20,902 & 18,554 & 20,151 & 24,177 & 21,804 \\
\hline 5793 & PA & 774 & 259 & 829 & 4519 & 3553 & 3544 & 3539 & 3442 & 3448 & 3436 & 3808 & 3785 & 3661 & 4207 & 4215 & 4236 & 4338 \\
\hline 5793 & PA & 774 & 207 & 829 & 11,123 & 20,879 & 20,988 & 21,055 & 15,976 & 15,643 & 16,261 & 15,615 & 16,057 & 17,339 & 16,520 & 17,296 & 19,301 & 18,524 \\
\hline 5793 & PA & 774 & 224 & 829 & 11,746 & 11,450 & 11,481 & 11,499 & 9492 & 9366 & 9598 & 9679 & 9840 & 10,235 & 10,388 & 10,714 & 11,539 & 11,405 \\
\hline 5793 & PA & 788 & 259 & 796 & 2845 & 1550 & 1532 & 1521 & 1587 & 1625 & 1556 & 2278 & 2099 & 1717 & 2259 & 2148 & 1935 & 2337 \\
\hline 5793 & PA & 788 & 207 & 796 & 10,277 & 9720 & 9683 & 9662 & 7791 & 7790 & 7795 & 9791 & 9341 & 8568 & 9324 & 9281 & 9319 & 9792 \\
\hline Unknown & PA & 760 & 221 & 893 & 34,955 & 27,912 & 28,258 & 28,469 & 21,750 & 20,979 & 22,412 & 20,816 & 23,013 & 28,949 & 20,282 & 22,092 & 26,686 & 24,039 \\
\hline Unknown & PA & 774 & 221 & 857 & 18,583 & 12,899 & 12,940 & 12,965 & 10,524 & 10,369 & 10,656 & 13,013 & 13,323 & 14,184 & 11,389 & 11,782 & 12,779 & 12,557 \\
\hline Unknown & PA & 777 & 193 & 850 & 24,994 & 30,499 & 30,675 & 30,782 & 21,942 & 21,427 & 22,385 & 25,303 & 25,984 & 28,402 & 22,219 & 23,336 & 26,306 & 24,288 \\
\hline Unknown & PA & 788 & 193 & 822 & 15,975 & 16,137 & 16,112 & 16,098 & 12,090 & 12,009 & 12,163 & 17,522 & 16,951 & 16,272 & 13,793 & 13,904 & 14,384 & 14,544 \\
\hline Unknown & PA & 788 & 179 & 822 & 24,951 & 27,089 & 27,108 & 27,121 & 18,942 & 18,690 & 19,164 & 26,190 & 25,582 & 25,340 & 20,577 & 21,013 & 22,414 & 22,110 \\
\hline Unknown & PA & 802 & 179 & 786 & 12,187 & 12,400 & 12,298 & 12,239 & 9116 & 9185 & 9066 & 16,570 & 15,044 & 12,708 & 11,459 & 11,129 & 10,687 & 11,758 \\
\hline Unknown & PA & 802 & 165 & 786 & 18,363 & 21,500 & 21,374 & 21,301 & 14,689 & 14,694 & 14,696 & 25,338 & 23,241 & 20,295 & 17,527 & 17,259 & 17,120 & 18,490 \\
\hline Unknown & PA & 816 & 165 & 751 & 10,122 & 9811 & 9669 & 9585 & 7061 & 7210 & 6945 & 16,035 & 13,692 & 10,228 & 9733 & 9122 & 8157 & 9935 \\
\hline
\end{tabular}

Case 1: Data Set $=$ All Data, Average TS values, $Q_{C}^{*}$ Determination Method $=$ Arrhenius Plot, $Q_{C}^{*}=284, u=0.0975, k_{1}=12.9$. Case 2: Data Set $=$ All Data, Average TS values, $Q_{C}^{*}$ Determination Method = Correlation Optimization, $Q_{C}^{*}=289, u=0.0971, k_{1}=13.5$. Case 3: Data Set $=$ All Data, Average TS values, $Q_{C}^{*}$ Determination Method $=$ Self-diffusion Activation $Q_{C}^{*}=292, u=0.0969, k_{1}=13.8$. Case 4: Data Set $=$ All Data, Heat- and processing-specific TS values, $Q_{C}^{*}$ Determination Method $=$ Arrhenius Plot, $Q_{C}^{*}=283, u=0.114, k_{1}=18.4$. Case 5: Data Set $=$ All Data, Heat- and processing-specific TS values, $Q_{C}^{*}$ Determination Method $=$ Correlation Optimization, $Q_{C}^{*}=272, u=0.115, k_{1}=16.3$. Case 6: Data Set $=$ All Data, Heatand processing-specific TS values, $Q_{C}^{*}$ Determination Method $=$ Self-diffusion Activation, $Q_{C}^{*}=292, u=0.113, k_{1}=20.2$. Case 7: Data Set $=$ Data with $t_{r}<10,000 \mathrm{~h}$, Average TS values, $Q_{C}^{*}$ Determination Method $=$ Arrhenius Plot, $Q_{C}^{*}=150, u=0.132, k_{1}=3.91$. Case 8: Data Set $=$ Data with $t_{r}<10,000 \mathrm{~h}$, Average TS values, $Q_{C}^{*}$ Determination Method $=$ Correlation Optimization, $Q_{C}^{*}=196, u=0.126, k_{1}=7.20$. Case 9: Data Set $=$ Data with $t_{r}<10,000 \mathrm{~h}$, Average TS values, $Q_{C}^{*}$ Determination Method $=$ Self-diffusion Activation, $Q_{C}^{*}=292, u=0.111$, $k_{1}=19.9$. Case 10: Data Set $=$ Data with $t_{r}<10,000 \mathrm{~h}$, Heat- and processing-specific TS values, $Q_{C}^{*}$ Determination Method $=$ Arrhenius Plot, $Q_{C}^{*}=207, u=0.126, k_{1}=8.32$. Case 11: Data Set $=$ Data with $t_{r}<10,000 \mathrm{~h}$, Heat- and processing-specific TS values, $Q_{C}^{*}$ Determination Method $=$ Correlation Optimization, $Q_{C}^{*}=235, u=0.122, k_{1}=11.6$. Case 12 : Data Set $=$ Data with $t_{r}<10,000 \mathrm{~h}$, Heat- and processing-specific TS values, $Q_{C}^{*}$ Determination Method = Self-diffusion Activation, $Q_{C}^{*}=292, u=0.114, k_{1}=20.9$. 


\section{References}

1. Purgert, R.; Shingledecker, J.; Pschirer, J.; Ganta, R.; Weitzel, P.; Sarver, J.; Vitalis, B.; Gagliano, M.; Stanko, G.; Tortorelli, P. Boiler Materials for Ultra Supercritical Coal Power Plants; Report No. DOE-EIO-EPRI-01NT41175; US Department of Energy: Washington, DC, USA, 2016. [CrossRef]

2. Tortorelli, P.F.; Wang, H.; Unocic, K.A.; Santella, M.L.; Shingledecker, J.P.; Cedro III, V. Long-Term Creep-Rupture Behavior of Inconel ${ }^{\circledR} 740$ and Haynes ${ }^{\circledR}$ 282. In Proceedings of the ASME 2014 Symposium on Elevated Temperature Application of Materials for Fossil, Nuclear, and Petrochemical Industries, Seattle, WA, USA, 25-27 March 2014. [CrossRef]

3. Viswanathan, R.; Hawk, J.; Schwant, R.; Saha, D.; Totemeier, T.; Goodstine, S.; McNally, M.; Allen, D.B.; Purgert, R. Steam Turbine Materials for Ultrasupercritical Coal Power Plants; US Department of Energy: Washington, DC, USA, 2009. [CrossRef]

4. $\quad$ Purgert, R.; Shingledecker, J.; Saha, D.; Thangirala, M.; Booras, G.; Powers, J.; Riley, C.; Hendrix, H. Materials for Advanced Ultrasupercritical Steam Turbines; US Department of Energy: Washington, DC, USA, 2015. [CrossRef]

5. Wilshire, B.; Battenbough, A.J. Creep and creep fracture of polycrystalline copper. Mater. Sci. Eng. A 2007, 443, 156-166. [CrossRef]

6. Wilshire, B.; Scharning, P.J. A new methodology for analysis of creep and creep fracture data for 9-12\% chromium steels. Int. Mater. Rev. 2008, 53, 91-104. [CrossRef]

7. Arrhenius, S.A. Über die Dissociationswärme und den Einfluß der Temperatur auf den Dissociationsgrad der Elektrolyte. Z. Phys. Chem. 1889, 4, 96-116. [CrossRef]

8. Norton, F.H. The Creep of Steels at High Temperatures; McGraw-Hill: New York, NY, USA, 1929.

9. Monkman, F.C.; Grant, N.J. An empirical relationship between rupture life and minimum creep rate in creep-rupture tests. Proc. Am. Soc. Test Mater. 1956, 56, 593-620.

10. Bonora, N.; Esposito, L. Mechanism based creep model incorporating damage. J. Eng. Mater. Technol. 2010, 132, 021013. [CrossRef]

11. Esposito, L.; Bonora, N.; De Vita, G. Creep modelling of $316 \mathrm{H}$ stainless steel over a wide range of stress. Proc. Struct. Int. 2016, 2, 927-933. [CrossRef]

12. Abdallah, Z.; Gray, V.; Whittaker, M.; Perkins, K. A critical analysis of the conventionally employed creep lifing methods. Materials 2014, 5, 3371-3398. [CrossRef]

13. Bolton, J. Reliable analysis and extrapolation of creep rupture data. Int. J. Pres. Ves. Pip. 2017, 157, 1-19. [CrossRef]

14. Larson, F.R.; Miller, J. A Time-Temperature Relationship for Rupture and Creep Stresses. Trans. ASME 1952, 74, 765-771.

15. Dagra Data Digitizer. Available online: http://www.datadigitization.com/ (accessed on 2 May 2018).

16. Lillo, T. High Temperature Alloy 617 Properties for Engineering Design: Program Overview \& Approach to ASME Code Qualification. In Proceedings of the Technical Meeting on High-Temperature Qualification of High Temperature Gas Cooled Reactor Materials, Vienna, Austria, 10-13 June 2014.

17. Schubert, F.; Bruch, U.; Cook, R.; Diehl, H.; Ennis, P.J.; Jakobeit, W.; Penkalla, H.J.; Heesen, E.T.; Ullrich, G. Creep rupture behavior of candidate materials for nuclear process heat applications. Nucl. Technol. 1984, 66, 227-240. [CrossRef]

18. Kim, W.G.; Park, J.Y.; Ekaputra, I.M.W.; Kim, S.J.; Kim, M.H.; Kim, Y.W. Creep deformation and rupture behavior of Alloy 617. Eng. Fail. Anal. 2015, 58, 441-451. [CrossRef]

19. Kim, W.G.; Ekaputra, I.M.W.; Park, J.Y.; Kim, M.H.; Kim, Y.W. Investigation of creep rupture properties in air and He environments of alloy 617 at $800{ }^{\circ}$ C. Nucl. Eng. Des. 2016, 306, 177-185. [CrossRef]

20. Ren, W.; Swindeman, R.W. Assessment of Existing Alloy 617 Data for Gen IV Materials Handbook; Report No. ORNL/TM-2005/510; US Department of Energy: Washington, DC, USA, 2015. [CrossRef]

21. Saha, D.; (General Electric Company, Power \& Water Division, Schenectady, NY, USA). Personal communication, 2012.

22. Cedro, V., III; Garcia, C.; Render, M. Use of the Wilshire Equations to Correlate and Extrapolate Creep Data of HR6W and Sanicro 25. Materials 2018, 11, 1585. [CrossRef] [PubMed]

23. Wilshire, B.; Scharning, P.J.; Hurst, R. New methodology for long term creep data generation for power plant components. Energy Mater. 2007, 2, 84-88. [CrossRef] 
24. Wilshire, B.; Scharning, P.J. Theoretical and practical approaches to creep of Waspaloy. Mater. Sci. Technol. 2009, 25, 242-248. [CrossRef]

25. Wilshire, B.; Scharning, P.J. Prediction of long term creep data for forged $1 \mathrm{Cr}-1 \mathrm{Mo}-0.25 \mathrm{~V}$ steel. Mater. Sci. Technol. 2008, 24, 1-9. [CrossRef]

26. Wilshire, B.; Scharning, P.J. Long-term creep life prediction for a high chromium steel. Scr. Mater. 2007, 56, 701-704. [CrossRef]

27. Wilshire, B.; Scharning, P.J. Extrapolation of creep life data for $1 \mathrm{Cr}-0.5$ Mo steel. Int. J. Pres. Ves. Pip. 2008, 85, 739-743. [CrossRef]

28. Wilshire, B.; Scharning, P.J. Creep and creep fracture of commercial aluminum alloys. J. Mater. Sci. 2008, 43, 3992-4000. [CrossRef]

29. Wilshire, B.; Scharning, P.J.; Hurst, R. A new approach to creep data assessment. Mater. Sci. Eng. A 2009, 510, 3-6. [CrossRef]

30. Wilshire, B.; Whittaker, M.T. The role of grain boundaries in creep strain accumulation. Acta Mater. 2009, 57, 4115-4124. [CrossRef]

31. Wilshire, B.; Scharning, P.J. Creep ductilities of 9-12\% chromium steels. Scr. Mater. 2007, 56, $1023-1026$. [CrossRef]

32. Whittaker, M.T.; Harrison, W.J. Evolution of Wilshire equations for creep life prediction. Mater. High Temp. 2014, 31, 233-238. [CrossRef]

33. Whittaker, M.T.; Evans, M.; Wilshire, B. Long-term creep data prediction for type $316 \mathrm{H}$ stainless steel. Mater. Sci. Eng. A 2012, 552, 145-150. [CrossRef]

34. Whittaker, M.T.; Harrison, W.J.; Lancaster, R.J.; Williams, S. An analysis of modern creep lifing methodologies in the titanium alloy Ti6-4. Mater. Sci. Eng. A 2013, 577, 114-119. [CrossRef]

35. Jeffs, S.P.; Lancaster, R.J.; Garcia, T.E. Creep lifing methodologies applied to a single crystal superalloy by use of small scale test techniques. Mater. Sci. Eng. A 2015, 636, 529-535. [CrossRef]

36. Whittaker, M.T.; Wilshire, B. Long term creep life prediction for Grade $22(2.25 \mathrm{Cr}-1 \mathrm{Mo})$ steels. Mater. Sci. Technol. 2011, 27, 642-647. [CrossRef]

37. Gray, V.; Whittaker, M. The changing constants of creep: A letter on region splitting in creep lifing. Mater. Sci. Eng. A 2015, 632, 96-102. [CrossRef]

38. Whittaker, M.; Wilshire, B. Creep and creep fracture of $2.25 \mathrm{Cr}-1.6 \mathrm{~W}$ steels (Grade 23). Mater. Sci. Eng. A 2010, 527, 4932-4938. [CrossRef]

39. Whittaker, M.; Wilshire, B. Advanced procedures for long-term creep data prediction for 2.25 chromium steels. Metall. Mater. Trans. A 2013, 44, 136-153. [CrossRef]

40. Whittaker, M.; Harrison, W.; Deen, C.; Rae, C.; Williams, S. Creep deformation by dislocation movement in Waspaloy. Materials 2017, 10, 61. [CrossRef] [PubMed]

41. Evans, M. A Re-Evaluation of the Causes of Deformation in $1 \mathrm{Cr}-1 \mathrm{Mo}-0.25 \mathrm{~V}$ Steel for Turbine Rotors and Shafts Based on iso-Thermal Plots of the Wilshire Equation and the Modelling of Batch to Batch Variation. Materials 2017, 10, 575. [CrossRef] [PubMed]

42. Zhu, X.W.; Cheng, H.H.; Shen, M.H.; Pan, J.P. Determination of C Parameter of Larson-miller Equation for 15CrMo steel. Adv. Mater. Res. 2013, 791, 374-377. [CrossRef]

43. MacEwan, J.R.; MacEwan, J.U.; Yaffe, L. Self-diffusion in polycrystalline Nickel. Can. J. Chem. 1959, 37, 1623-1628. [CrossRef]

44. Whittaker, M.; Wilshire, B.; Brear, J. Creep fracture of the centrifugally-cast superaustenitic steels, HK40 and HP40. Mater. Sci. Eng. A 2013, 580, 391-396. [CrossRef]

45. Fujio, A.; Tabuchi, M.; Hayakawa, M. Influence of Data Scattering on Estimation of 100,000 hrs Creep Rupture Strength of Alloy 617 at $700{ }^{\circ} \mathrm{C}$ by Larson-Miller Method. J. Press. Vessel Technol. 2017, 139, 011403. [CrossRef]

46. Woo-Gon, K.; Yin, S.N.; Kim, Y.W.; Ryu, W.S. Creep behaviour and long-term creep life extrapolation of alloy 617 for a very high temperature gas-cooled reactor. Trans. Indian Inst. Met. 2010, 63, 145-150. [CrossRef]

47. ECCC Data Sheets 2017. Available online: http://eccc.c-s-m.it/layout_html_standard/en/eccc_european_ creep_collaborative_committee/eccc_data_sheets_2017.html (accessed on 21 August 2018).

48. Bullough, C.; Krein, R.; Lombardi, P.; Spindler, M.; Poggio, E. Development of an ECCC Interim Creep Rupture Datasheet for Alloy 617B using a Strength Averaging and Blending Approach. In Proceedings of the 4th International ECCC Creep \& Fracture Conference, Düsseldorf, Germany, 10-14 September 2017. 
49. Evans, M. A Statistical Test for Identifying the Number of Creep Regimes When Using the Wilshire Equations for Creep Property Predictions. Metall. Mater. Trans. A 2016, 47, 6593-6607. [CrossRef]

50. Evans, M. Incorporating specific batch characteristics such as chemistry, heat treatment, hardness and grain size into the Wilshire equations for safe life prediction in high temperature applications: An application to 12Cr stainless steel bars for turbine blades. Appl. Math. Model. 2016, 40, 10342-10359. [CrossRef]

51. Evans, M. Formalisation of Wilshire-Scharning methodology to creep life prediction with application to 1Cr-1Mo-0.25V rotor steel. Mater. Sci. Technol. 2010, 26, 309-317. [CrossRef]

52. Evans, M. Obtaining confidence limits for safe creep life in the presence of multi batch hierarchical databases: An application to 18Cr-12Ni-Mo steel. Appl. Math. Model. 2011, 35, 2838-2854. [CrossRef]

53. Evans, M. The importance of creep strain in linking together the Wilshire equations for minimum creep rates and times to various strains (including the rupture strain): An illustration using $1 \mathrm{CrMoV}$ rotor steel. J. Mater. Sci. 2014, 49, 329-339. [CrossRef]

54. Evans, M. Constraints Imposed by the Wilshire Methodology on Creep Rupture Data and Procedures for Testing the Validity of Such Constraints: Illustration Using 1Cr-1Mo-0.25 V Steel. Metall. Mater. Trans. A 2015, 46, 937-947. [CrossRef]

(C) 2018 by the authors. Licensee MDPI, Basel, Switzerland. This article is an open access article distributed under the terms and conditions of the Creative Commons Attribution (CC BY) license (http:/ / creativecommons.org/licenses/by/4.0/). 